Winter 1-1-2010

\title{
Recent advances on skin-resident stem/progenitor cell functions in skin regeneration, aging and cancers and novel anti-aging and cancer therapies.
}

Murielle Mimeault

University of Nebraska Medical Center

Surinder K. Batra

University of Nebraska Medical Center, sbatra@unmc.edu

Tell us how you used this information in this short survey.

Follow this and additional works at: https://digitalcommons.unmc.edu/com_bio_articles

Part of the Medical Biochemistry Commons, and the Medical Molecular Biology Commons

\section{Recommended Citation}

Mimeault, Murielle and Batra, Surinder K., "Recent advances on skin-resident stem/progenitor cell functions in skin regeneration, aging and cancers and novel anti-aging and cancer therapies." (2010). Journal Articles: Biochemistry \& Molecular Biology. 81.

https://digitalcommons.unmc.edu/com_bio_articles/81

This Article is brought to you for free and open access by the Biochemistry \& Molecular Biology at DigitalCommons@UNMC. It has been accepted for inclusion in Journal Articles: Biochemistry \& Molecular Biology by an authorized administrator of DigitalCommons@UNMC. For more information, please contact digitalcommons@unmc.edu. 


\title{
Recent advances on skin-resident stem/progenitor cell functions in skin regeneration, aging and cancers and novel anti-aging and cancer therapies
}

\author{
Murielle Mimeault $^{\text {a, b, * }}{ }^{\text {, Surinder K. Batra }}{ }^{\text {a, b, c }}$ \\ ${ }^{a}$ Department of Biochemistry and Molecular Biology, University of Nebraska Medical Center, Omaha, NE, USA \\ ${ }^{b}$ Eppley Institute for Research on Cancer and Allied Diseases, University of Nebraska Medical Center, Omaha, NE, USA \\ ${ }^{c}$ Department of Pathology and Microbiology, University of Nebraska Medical Center, Omaha, NE, USA
}

Received: March 14, 2009; Accepted: August 11, 2009

- Introduction

- Functions of skin-resident adult stem/progenitor cells in skin regeneration

- Altered functions of skin-resident adult stem/progenitor cells during chronological aging

- Potential implications of skin-resident stem/progenitor cells in skin aging-related disorders

- Animal models of skin-resident stem/progenitor cell aging and disorders

- Altered functions of skin-resident adult stem/progenitor cells in skin hyperproliferative disorders and cancers

- Potential implications of cancer stem/progenitor cells in basal cell and squamous cell cancers
- Potential implications of cancer stem/progenitor cells in melanoma

- Molecular events associated with melanoma progression

- Novel stem cell-based therapies

- Novel anti-aging therapies

- Modulation of aging process by calorie restriction and pharmacological agents

- Novel cell-replacement and gene therapies

- Novel cancer therapies targeting skin cancer stem/progenitor cells and their microenvironment

- Conclusions and future directions

\begin{abstract}
Recent advances in skin-resident adult stem/progenitor cell research have revealed that these immature and regenerative cells with a high longevity provide critical functions in maintaining skin homeostasis and repair after severe injuries along the lifespan of individuals. The establishment of the functional properties of distinct adult stem/progenitor cells found in skin epidermis and hair follicles and extrinsic signals from their niches, which are deregulated during their aging and malignant transformation, has significantly improved our understanding on the etiopathogenesis of diverse human skin disorders and cancers. Particularly, enhanced ultraviolet radiation exposure, inflammation and oxidative stress and telomere attrition during chronological aging may induce severe DNA damages and genomic instability in the skin-resident stem/progenitor cells and their progenies. These molecular events may result in the alterations in key signalling components controlling their self-renewal and/or regenerative capacities as well as the activation of tumour suppressor gene products that trigger their growth arrest and senescence or apoptotic death. The progressive decline in the regenerative functions and/or number of skin-resident adult stem/progenitor cells may cause diverse skin diseases with advancing age. Moreover, the photoaging, telomerase re-activation and occurrence of different oncogenic events in skin-resident adult stem/progenitor cells may also culminate in their malignant transformation into cancer stem/progenitor cells and skin cancer initiation and progression. Therefore, the anti-inflammatory and anti-oxidant treatments and stem cell-replacement and gene therapies as well as the molecular targeting of their malignant counterpart, skin cancer-initiating cells offer great promise to treat diverse skin disorders and cancers.
\end{abstract}

Keywords: skin-resident adult stem/progenitor cells $\bullet$ senescence $\bullet$ aging $\bullet$ skin cancer stem/progenitor cells $\bullet$ anti-aging therapies $\bullet$ cancer therapies $\bullet$ molecular targeting

${ }^{*}$ Correspondence to: Murielle MIMEAULT, Ph.D., Department of Biochemistry and Molecular Biology, Eppley Institute for Research in Cancer and Allied Diseases, University of Nebraska Medical Center, Omaha,
NE 68198-5870, USA.

Tel.: (402)559-5455

Fax: (402)559-6650

E-mail:mmimeault@unmc.edu 


\section{Introduction}

Human skin epidermis and its appendages exhibit different site-specific morphologies and very important physiological functions including the protection against environmental injury, infection and excessive dehydration, corporal temperature regulation, and hair growth maintenance [1-6]. The skin integrity and barrier function are tightly regulated by a complex network of cell-cell and cell-matrix interactions. In particular, the cellular regeneration of skin epidermis and hair follicles is maintained along lifespan of individuals by different adult stem/progenitor cell subpopulations localized within the specialized microenvironments, niches in basal layer of epidermis, sebaceous gland and hair follicle bulge region (Fig. 1) [7-20]. These small subpopulations of immature cells endowed with a high self-renewal capacity and multilineage differentiation ability contribute to replenish the different skin cell lineages, including mature and specialized keratinocytes, sebocytes or melanocytes, in homeostatic conditions or after intense skin injuries. A chronic or cumulative ultraviolet-light (UV) exposure and inflammation of skin and oxidative stress and telomere shortening in skin stem/progenitor cells and their progenies, however, usually lead to their dysfunctions or loss via the senescence or apoptotic death with advancing age (Figs 1 and 2) [21-28]. This age-related decline in skin regenerative cells may result in a skin homeostatic imbalance and severe cutaneous disorders [23-28]. In particular, a long-term exposure of skin cells to environmental insults such as UV radiations and internal metabolic reactions typically generates highly toxic products and reactive free radicals [1, 3, 21, 23, 25-27, $29,30]$. These molecular events may cause severe damages to mitochondrial and nuclear DNA, membranes, lipids and proteins in skin-resident stem/progenitor cells and their progenies as well as dermal fibroblasts, and ultimately lead to cell dysfunctions or loss during chronological aging. Of therapeutic interest, numerous therapeutic approaches have been developed to restore the skin integrity and functions with advancing age and improve the repair mechanisms after severe injuries. The use of antioxidants, antiinflammatory and detoxifying agents, calorie restriction and stem cell-based therapies have emerged as the promising strategies to prevent or delay the functional decline or loss of skin-resident adult stem/progenitor cells and their progenies occurring during chronological aging or photoaging [25, 28, 31-43]. These anti-aging strategies, which may improve the stress resistance and survival of skin regenerative cells, represent the potential therapies to prevent the age-related skin detrimental alterations and disorders such as premature aging diseases, chronic non-healing wounds and ulcers and ectodermal dysplasia [25, 28, 31-43].

In addition, the photoaging and accumulation of genetic and/or epigenetic alterations in skin stem/progenitor cells and their progenies as well as their microenvironment, including age-related changes in the expression levels of numerous gene products, may lead to development of cutaneous basal cell and squamous cell cancers (BCCs and SCCs) or aggressive and recurrent melanoma (Fig. 1) [1, 4, 6, 13, 22, 28, 44-52]. More specifically, telomere attrition, the gene mutations leading to inactivation of diverse tumour suppressor gene products $\left[\mathrm{p} 16^{\mathrm{INK} 4 \mathrm{~A}}, \mathrm{p} 19^{\mathrm{ARF}}\right.$, retinoblastoma ( $p R b)$ and/or p53] combined with a sustained stimulation of diverse developmental signalling cascades initiated by distinct growth factors, and defects in DNA repair mechanisms may contribute to skin cancer initiation and progression (Figs 2 and 3 ) $[1,6,13,28,44-55]$. Among the growth factor cascades that are often deregulated in skin cancer stem/progenitor cells and their progenies, there are hedgehog, epidermal growth factor receptor (EGFR), Wingless (Wnt)/ $\beta$-catenin, Notch, Nodal/Cripto-1, extracellular matrix (ECM)/integrins and/or Polycomb group protein BIM-1 signalling pathways (Fig. 3). In support with the critical functions of skin cancer stem/progenitor cells in the skin cancer development and metastases, small subpopulations of highly tumorigenic cancer cells with stem cell-like properties have been identified in situ and isolated from BCCs, SCCs and primary and secondary melanoma tumours and established skin cancer cell lines [44, 56-66]. In addition, the development of skin cancers is generally accompanied by extensive changes in the local microenvironment of skin cancer stem/progenitor cells and their progenies including in their niches and ECM components as well as the secretion of diverse paracrine mitotic factors by activated stromal cells that contribute to their acquisition of a more malignant behaviour (Fig. 1) [1, 2, 28, 67-69]. Therefore, the molecular targeting of distinct deregulated oncogenic products in skin cancer stem/ progenitor cells and their microenvironment offers great promise to eradicate the total cancer cell mass including skin cancerinitiating cells and their progenies, and thereby improve the current cancer therapies.

In this article, we reviewed the specific functions provided by each adult stem/progenitor cell type in skin maintenance and regeneration as well as their potential implications in the development of age-related skin disorders and cancers. The emphasis is on the molecular and cellular mechanisms associated with dysfunctions or loss of skin-resident adult stem/progenitor cells and their progenies during chronological aging as well as new anti-aging and cancer therapies to treat a diversity of severe skin disorders and aggressive cancers.

\section{Functions of skin-resident adult stem/ progenitor cells in skin regeneration}

The cellular regeneration of the skin is maintained by different adult stem/progenitor cell subpopulations localized within the specialized microenvironments, niches in interfollicular epidermis (IFE), sebaceous gland and hair follicle bulge region (Fig. 1) [7-20, 70-72]. The epidermal barrier is affected by a continuous loss of terminally differentiated keratinocytes in the outermost epidermal layer, the stratum corneum that are shed from the skin surface during the desquamation process $[1,6]$. The small clusters of 


\section{POTENTIAL CELLULAR EVENTS ASSOCIATED WITH THE CHRONOLOGICAL AGING OF SKIN STEMPROGENITOR CELLS AND DERMAL FIBROBLASTS}

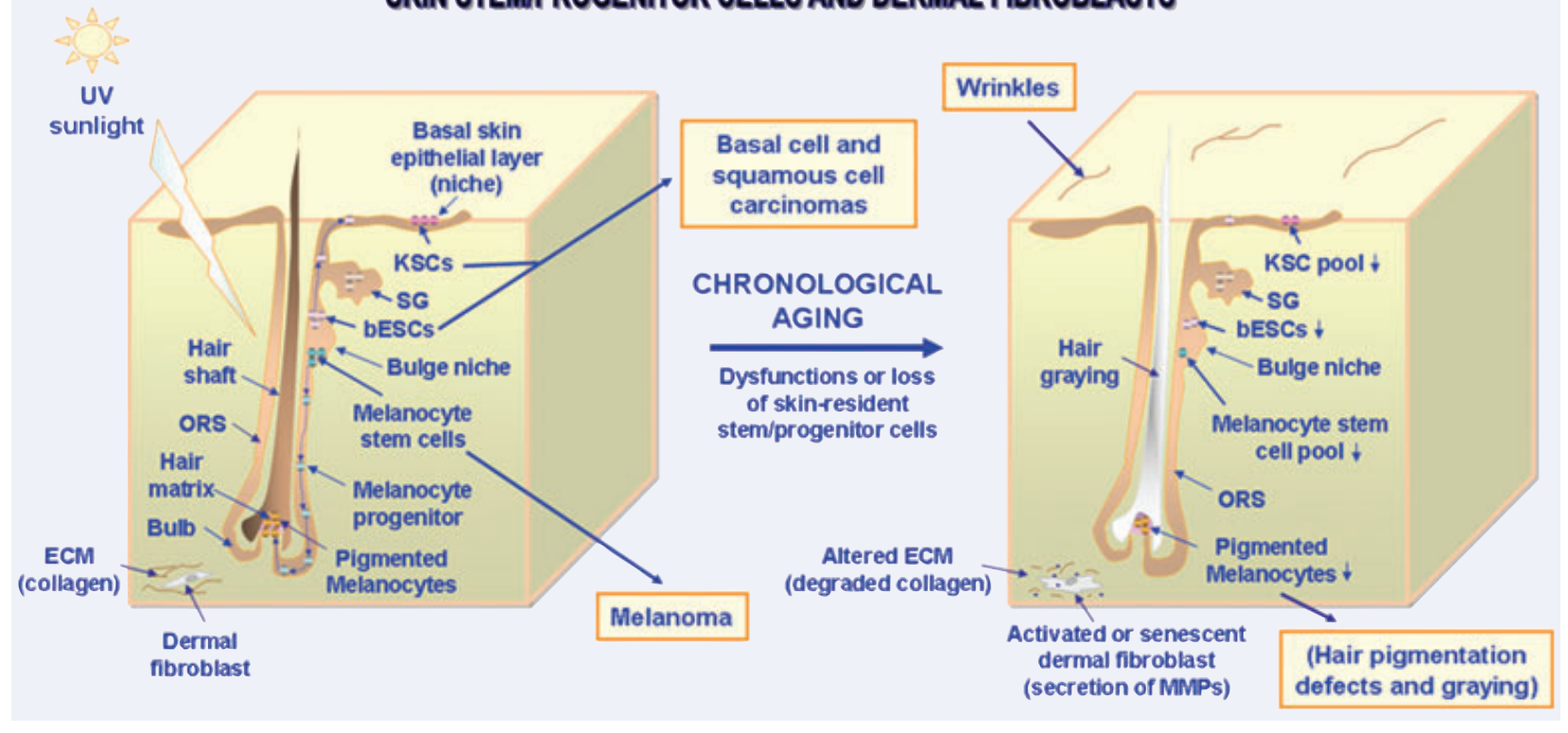

Fig. 1 Scheme showing the anatomical localization of skin-resident adult stem/progenitor cell niches and the potential cellular changes associated with the skin aging and cancers. The small pool of KSCs resident in basal layer of the epithelial compartment are able to regenerate the skin stratified epithelium by replenishing all of the differentiated epithelial keratinocytes, including terminally differentiated keratinocytes at the skin surface lost during desquamation process. Moreover, bESCs in the follicle hair may also replenish the keratinocytes constituting of appendages including sebeceous gland and interfollicular epithelium during the hair growth cycle and tissue regeneration after severe skin injury. Additionally, the bulge-resident melanocyte stem cells may generate the melanocyte precursors that can migrate via ORS to the germinal matrix at the bulg areas of each hair follicle, and thereby replenish the mature pigmented melanocytes that are responsible for the hair pigmentation by transferring melanin to keratinocytes. This scheme also shows the potential consequences of the chronological aging of skin stem/progenitor cells including the wrinkles and hair growth defects leading a decreased hair pigmentation (greying) and loss. Moreover, the skin cancers including basal cell and squamous cell carcinomas and melanoma which may derive from genetic alterations in KSCs, bESCs or melanocyte stem cells are indicated. The degradation of collagen in dermal layer through the release of MMPs by the activated or senescent dermal fibroblasts which may promote the development of skin disorders and invasive cancer subtype is also illustrated.

undifferentiated and unipotent keratinocyte stem cells (KSCs) with stem cell-like properties and expressing cytokeratins (CK5/14/15), p63, $\alpha_{6} \beta_{4}$ - and $\alpha_{3} \beta_{1}$-integrins, and ATP-binding cassette (ABC) transporters, have been identified near basement membrane in the basal layer of epithelial compartment (Fig. 1) [2, 7, 8, 10, 11, 13, $70,73]$. KSCs provide critical roles in participating to the continuous replenishment of mature keratinocytes of epidermis in homeostatic conditions and after skin injuries [7, 11, 13, 14]. A complex network of signalling cascades such as EGFR, Notch, insulin-like growth factor (IGF-1)/IGF-R1, immunoglobulin-like domains 1 (Lrig1), Myc, transforming growth factor- $\beta$ (TGF- $\beta$ ) and Polycomb-group protein BMI-1 is involved in the stringent regulation of KSCs behaviour [6, 8-11, 70, 74-79]. The integration of these diverse signalling pathways in KSCs may result in their proliferation and/or differentiation into keratinocytes during skin tissue regeneration. In this regard, an asymmetric division of KSCs generates the transit amplifying (TA)/intermediate cells [80]. TA cells in turn migrate outside the niche and give rise to the intermediate keratinocytes and more committed terminally differentiated keratinocytes constituting various epidermal layers of the skin [80]. The down-regulation of EGFR in KSCs concomitant with an enhanced activity of p53 and expression of its targets Notch1 and p21 $1^{\text {WAF } 1 / C I P 1}$ may notably promote the keratinocyte differentiation [81-83]. Moreover, other signalling effectors, including inhibitor of $\kappa \mathrm{B}\left(\mathrm{I}_{\kappa} \mathrm{B}\right)$ kinase- $\alpha$ (IKK- $\left.\alpha\right)$, interferon regulatory factor 6 (IRF6) and cell cycle regulator protein stratifin (SFN, also designated as $14-3-3 \sigma$ protein) also provide critical functions in the regulatory processes controlling keratinocyte proliferation-differentiation switch from a mitotic state to a terminally differentiated state [73, 84-89]. Additional studies are however necessary to establish the precise roles of IRF6, IKK- $\alpha$ and SFN in KSC behaviour versus their differentiated progenies.

In addition, a small subset of unipotent progenitor cells expressing CK5/14 and B-lymphocyte-induced maturation protein 


\section{POTENTILL MOLECULAR EVENTS ASSOCLATED WTH THE CHRONOLOGICALAGING AND MALGGANT TRANSFORMATION OF SKIN STEMPROGENTOR CELLS}

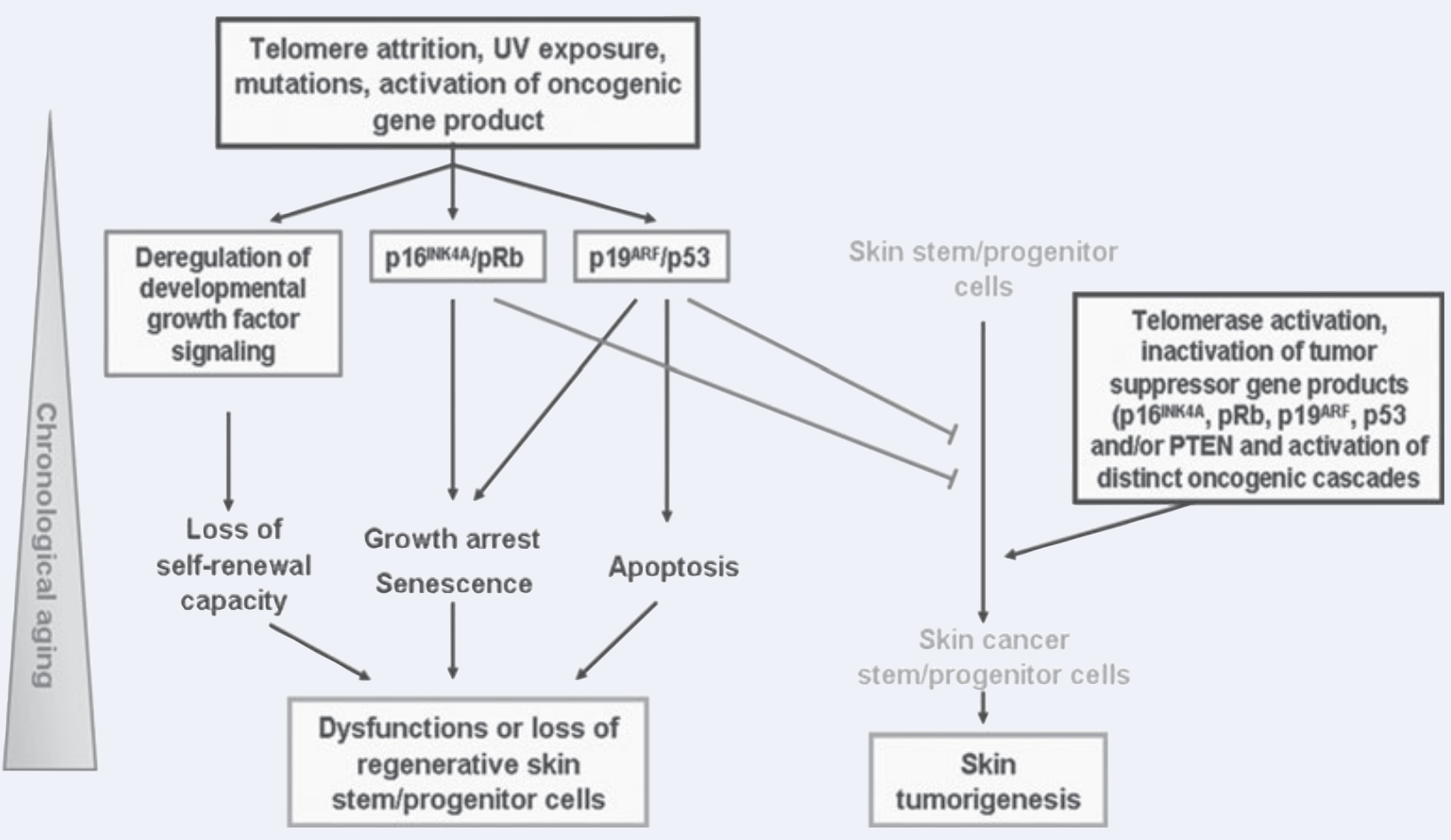

Fig. 2 Schematic representation of possible molecular events associated with the dysfunctions or loss of skin-resident stem/progenitor cells. This scheme suggests that telomere shortening, mutations, DNA repair defects and/or a long-term ultraviolet (UV) exposure of skin-resident stem/progenitor cells during chronological aging may be accompanied by a decline of their functions or loss. Particularly, the alterations in the growth factor signalling pathways involved in the stringent control of the self-renewal capacity of these immature cells may lead to their dysfunction. Moreover, the enhanced expression levels and activation of the $\mathrm{p} 16^{\mathrm{INK} 4 \mathrm{~A}} /$ retinoblastoma $(\mathrm{Rb})$ and $\mathrm{p} 19^{\mathrm{ARF}} / \mathrm{p} 53$ cascades may result in an inhibition of CDK/cyclin complexes, inactivation of the E2F transcription factor and growth arrest or senescence. In addition, p53-induced pro-apoptotic factors including Bax, may also trigger the apoptotic death of these skin regenerative cells with advancing age. In addition, this scheme also specifies that the tumour-suppressing effect mediated through the $\mathrm{p} 16^{\text {INK4A }}$ - and/or p53-initaited pathways may counteract the malignant transformation of skin cancer-initiating cells. Alternatively, the telomerase activation combined with the occurrence of distinct genetic and/or epigenetic alterations leading to inactivation of tumour suppressor genes and sustained activation of diverse developmental pathways in skin stem/progenitor cells may culminate in their malignant transformation into skin cancer stem/progenitor cells and skin tumour formation.

1 (BLIMP1) has also been identified near basement membrane surrounding the cutaneous sebaceous gland in the hair follicle (Fig. 1) [17]. These skin progenitor cells contribute to regenerate the sebaceous gland including the terminally differentiated sebocytes that provide important functions in the endocrine and hormonal regulation of skin integrity and sebum secretion $[5,17]$. Moreover, the multipotent epithelial stem cells (bESCs) expressing different markers such as CK5/14/15/19, CD200, p63, $\alpha_{6} \beta 4$ - and $\alpha_{3} \beta_{1}$-integrins have been identified in the bulge niche of the hair follicle (Fig. 1) [8, 9, 12, 15, 16, 22, 71, 90-93]. It has also been reported that murine bESC may be distinguished from KSCs on the basis of their CD34 expression while the CD34 marker is not expressed by human bESCs in bulge niche [12, 71, 94, 95]. A human $\mathrm{CD} 34^{+}$subpopulation resident in upper region of the outer root sheath (ORS) of the hair follicle, however, has been observed to more effectively regenerate new hair follicle in immunodeficient nude mouse than CD34- ${ }^{-}$cells suggesting that a large niche could be occupied by human ESCs [96]. bESCs or early progenies serve as a source of immature cells to regenerate the epidermal cells in skin appendages or damaged epithelial tissue in response to intense injuries (Fig. 1) [2, 7-9, 12-16, 22, 71, 92-94]. Indeed, the hair follicles typically undergo repeated growth cycles consisting 


\section{POTENTILL ONCOGENIC SIGNALING CASCADES INVOLVED IN MALIGNANT BEHAVIOR OF MELANOMA STEWPROGENTTOR CELLS AND THERAPEUTIC MOLECULAR TARGETS}

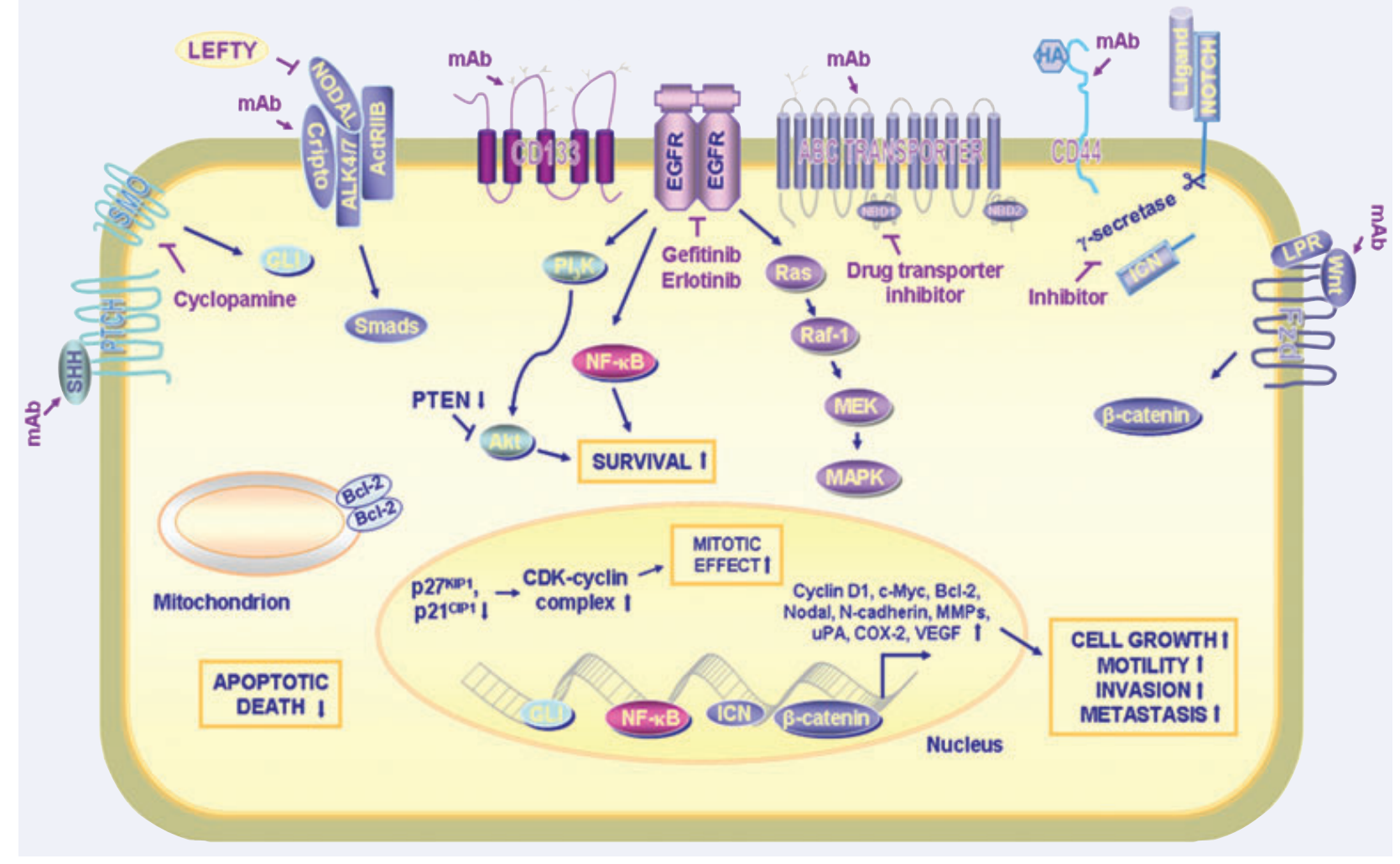

Fig. 3 Scheme showing the potential oncogenic cascades involved in the malignant and aggressive phenotypes of melanoma stem/progenitor cells. The intracellular signalling cascades induced through the activation of distinct growth factor pathways which may provide a critical role for the sustained growth, survival, migration, invasion, metastases and/or drug resistance of melanoma stem/progenitor cells, are shown. These tumorigenic cascades include sonic hedgehog SHH/PTCH (patched receptor)/GLI, Cripto-Nodal-ALK4/7/ActRIIB activin-like kinases receptor complex, CD133 pentaspan transmembrane protein, Notch/Ligand (Delta and Jagged), hyaluronan (HA)/CD44 and Wnt/Frizzled (Fzd)/ $\beta$-catenin. The up-regulated expression levels of certain target gene products including up-regulated cyclin D1, C-Myc, Bcl-2, Nodal, N-cadherin, matrix metalloproteinase (MMPs), urokinase plasminogen (UPA), cyclooxygenase (COX-2) and vascular epidermal growth factor (VEGF) that can contribute to the malignant transformation of melanoma stem/progenitor cells are also indicated. In addition, the potential molecular targeting strategies by using a selective inhibitor of SMO hedgehog signalling element (cyclopamine), Nodal (Lefty), EGFR (gefitinib or erlotinib), $\gamma$-secretase and monoclonal antibody (mAb) directed against Cripto-1, CD133 and $\mathrm{ABC}$ multidrug transporter.

to the periods of active growth (anagen), regression (catagen) and rest (telogen). During the hair cycle, the activation of quiescent bESC subpopulation leads to their division and generation of TA cells that in turn can leave the bulge niche and migrate along the ORS forming the outermost layer toward germinal matrix and dermal papilla where they can give rise to mature keratinocytes (Fig. 1). In this matter, it has been reported that the induction of telomerase or its catalytic subunit, telomerase reverse transcriptase (TERT) in mouse skin epithelium caused a rapid transition from the resting phase of hair follicle cycle (telogen) into the active phase (anagen) by activating hair follicle stem cell proliferation [97-100]. In fact, TERT may directly promote the entrance of quiescent hair follicle stem/progenitor cells into the cell cycle by modulating the Wnt and Myc pathways [98-101]. The interplay of a complex network of several developmental signalling cascades initiated by different growth factors as well as the changes in key niche components generally participate to the stringent regulation of bESC behaviour during hair follicle growth and/or IFE regeneration after severe injuries [13, 15, 22, 71, 93, 102-106]. These pathways include sonic hedgehog (SHH/PTCH/GLI), EGFR, Wnt/ $\beta$-catenin, Notch, nuclear factor-kappa B (NF-кB), bone morphogenic protein (BMP), BMI-1 and SOX9 transcription factor. Particularly, the activation of Wnt/ $\beta$-catenin pathway seems to be necessary for the fate specification of bESCs into hair follicular 
keratinocytes rather IFE keratinocytes during hair growth cycle while Notch signalling may contribute to the maintenance of the hair follicle fate of bESCs [103, 107-110].

The lower permanent portion of the hair follicle bulge region in human and mice also contains a small subpopulation of immature melanocyte stem cells with stem cell-like properties that can give rise to melanocyte precursors and mature melanocytes in bulb areas at the base of hair follicle (Fig. 1) [18, 21, 111-115]. The gene expression analyses of melanocyte stem cells isolated from murine hair follicles revealed that they express dopachrome tautomerase (Dct) and paired-box transcription factor PAX3 like melanocytes $[111,115]$. The undifferentiated melanocyte stem cells, however, may be distinguished from melanocyte precursors and mature melanocytes by a down-regulated expression of melanocyte-specific gene products such as microphtalmia-associated transcription factor (MITF), SRY (sex determining region Y)-box 10, S0X10 transcription factor, lymphoid enhancer-binding factor 1(LEF1), KIT and tyrosinase-related protein 1 (Tyrp1) [111, 115]. More specifically, during the anagen phase of hair follicle cycle, activated melanocyte stem cells in the hair follicle bulge region generate the melanocyte precursors that migrate along the ORS to regenerate the epidermal and hair matrix melanocytes (Fig. 1) [18, 21, 112]. The differentiated and pigmented melanocytes localized at the base of each hair follicle in the bulb areas provide critical functions in hair pigmentation by producing the specialized melanin-containing vesicles, melanosomes that are transferred to neighbouring keratinocytes. Numerous signalling pathways are involved in the stringent regulation of the maintenance of bulge-resident melanocyte stem cells in quiescent versus activated states as well as in their survival, proliferation, migration and differentiation into melanocyte lineage [18, 21, 113-123]. These signalling elements include Notch1 and 2, stem cell factor (SCF)/KIT, stromal cell-derived factor-1 (SDF1)/CXC chemokine receptor 4 (CXCR4), PAX3, MITF and anti-apoptotic factor, Bcl-2 [18, 21, 113-123].

In addition, different cell types, which may derive from pluripotent neural crest stem cells during embryonic development, may also be generated from bulge-resident stem cells or their progenitors in post-natal life in adult mammifers [19, 20, 113, 124-132]. More particularly, the bulge area in human hair follicle contains a small subpopulation of pluripotent epidermal neural crest stem cells (eNCSCs) expressing stem cell-like markers such as nestin, SOX9, Nanog and 0ct-3/4 that can give rise to multiple skin cell lineages including melanocytes, neurons and smooth muscle cells [20]. Another subpopulation of multipotent adult skin-derived precursors (SKPs), which reside within the dermal papillae of hair follicles, also appear to exhibit properties similar to those of eNCSCs [129, 130, 133]. SKPs can be expanded in the presence of EGF, basic fibroblast growth factor (bFGF) and TGF- $\beta$ and give rise to neurons, glia, smooth muscle cells, and adipocytes in culture in vitro. Additionally, it has also been reported that the multipotent human skin-derived $\mathrm{CD}_{133^{+}}$ cells expressing the CD34 and Thy- 1 antigens were able to proliferate in the presence of EGF and bFGF, form spheres, and differentiate into neurons, astrocytes, and rarely into oligodendrocytes in vitro as well as astrocytes and endothelium in vivo [134].
Future investigations are however necessary to establish the hierarchical organization of these skin-resident stem/progenitor cells, and more particularly, to determine whether bulge-resident melanocyte stem cells or SKPs may arise from more primitive eNCSCs as well as their specific functions in skin maintenance and cell regeneration after severe injuries.

On the other hand, the stromal cells including fibroblasts and dermal sheath cells (DSCs) as well as multipotent dermal-resident mesenchymal stem cells (MSCs) and endothelial progenitor cells (EPCs) have been detected in human dermis and vascular well of skin tissue, respectively [78, 135-137]. Hence, these skin cells can participate to skin regeneration and cutaneous wound healing through the release of diverse paracrine factors. More specifically, the differentiation of EPCs into mature endothelial cells may contribute to the formation of new vessels after severe skin injuries. Similarly, bone marrow (BM)-derived MSCs and EPCs can also migrate to severe injured cutaneous tissues such as non-healing chronic wounds, and thereby take part to skin repair and regeneration processes [135, 138, 139].

Collectively, these observations suggest that the interplay of different types of skin-resident adult stem/progenitor cells contribute to the maintenance of skin integrity and functions in homeostatic conditions and during tissue repair after severe injuries. Unfortunately, the dysfunctions, loss or malignant transformation of these rare regenerative skin-resident stem/progenitor cells during chronological aging or in pathological conditions may result in the development of severe skin disorders and cancers.

\section{Altered functions of skin-resident adult stem/progenitor cells during chronological aging}

The structural integrity and functions of skin are generally altered with passage of time [1, 3, 21, 25]. The chronological intrinsic aging of skin cells may result in a progressive decrease of turnover epidermal time and loss of tone and elasticity of skin [1, 3, 21, 25, 140]. Moreover, the skin aging is also accompanied by an increased susceptibility to injury and infection, epidermal dehydratation, reduced wound healing, wrinkles (rhytides), pigmentary alterations, hair greying and loss, blood vessels weakness, and increased risk of skin epithelial cancers and melanoma (Fig. 1) [1, 3, 21, 25-27, $140]$. Among the principal environmental factors that may promote the skin-aging process and ultimately carcinogenesis, a repeated exposure to solar UV radiations is critical [25, 27, 48, $49,54,141]$. Although the active repair mechanisms and melanin synthesis may protect the skin cells against UV radiation-induced cellular damages, a chronic or cumulative exposure to sunlight may induce several gene mutations and culminate to development of skin disorders such as epidermal 
atrophy, psoriasis, keratosis, depigmentation and dysplasia as well as skin cancer initiation.

\section{Potential implications of skin-resident stem/ progenitor cells in skin aging-related disorders}

Accumulating lines of experimental evidence have revealed that the chronological or premature aging of skin may be associated with dysfunctions or loss of certain skin-resident stem/progenitor cells (Figs 1 and 2) [24, 26-28, 97]. This decline in the functional properties or number of KSCs and bESCs with the time may impair the skin regeneration process and wound healing, and contribute to development of diverse skin disorders [10, 24, 26, 27, 97]. For instance, the results from a study carried out using the sunexposed and sun-protected skin samples obtained from old individuals revealed that the KSC number was lower in photoaged skin than in chronologically aged skin specimens [27]. Moreover, it has been reported that the telomere shortening may occur in hair follicle stem cells with aging, and thereby lead to DNA instability and a decline in their functional properties including their capacity to replenish mature and functional keratinocytes and melanocytes of follicle during the hair growth cycle [97].

The chronological aging and photoaging of skin is also accompanied by an extensive ECM remodelling in dermal layers such as the occurrence of EMT program or senescence of skin fibroblasts, dramatic up-regulation of matrix metalloproteinases (MMPs) and a decrease of collagen production (Fig. 1) [140, 142, 143]. Particularly, the fibroblasts in aged skin can produce high levels of matrix MMPs and low levels of collagen [142]. An exposure of human skin fibroblasts to UV irradiation may also result in oxidative stress and enhanced expression of $p 16^{\text {INK4A }}$ and p53/p21 ${ }^{\text {WAF1/CIP1 }}$-induced fibroblast premature senescence and/or the activation of the fibroblast to myofibroblast transition [29, 69, $143,144]$. These molecular events may lead to a loss of skin tone and elasticity, fibrosis and increased risk to develop aggressive and invasive skin cancers such as melanoma and morphoeic BCC subtype, which is characterized by an infiltrative growth pattern and densely fibrous stroma as compared to the most low-risk and indolent BCCs [29, 68, 69, 144].

In addition, diverse premature aging disorders, which are typically caused by inherited or sporadic genetic mutations in key gene products resulting in detrimental nuclear lamina alterations, an accelerated telomere attrition and/or DNA repair defects, are also associated with an accelerated apparition of skin aging phenotypes and premature death of patients [145-152]. The premature aging disorders include HutchinsonGilford progeria syndrome, Werner syndrome, dyskeratosis congenital, ataxia-telangiectasia, Fanconi anaemia, aplastic anaemia, xeroderma pigmentosum (XP), Cockayne syndrome and trichothiodystrophy [145-153]. In general, the genetic abnormalities associated with these diseases may lead to genomic instability and dysfunctions in adult stem/progenitor cells and their progenies in diverse tissues including skin. Hence, these accel- erated aging disorders may be accompanied by a premature loss of hair and subcutaneous fat, hair greying, severe skin atrophy and/or an enhanced propensity to develop diverse diseases including skin disorders and cancers [28, 148-161]. In this regard, several animal models have been developed to establish the cellular and molecular events that may promote the aging process and skin disorder development.

\section{Animal models of skin-resident stem/progenitor cell aging and disorders}

Several studies carried out on mice models have indicated the potential implication of the senescence or apoptotic death of skin-resident adult stem/progenitor cells and their progenies in acquisition of certain premature aging phenotypes and the pathophysiological development of age-related skin disorders $[21,97,116,119,152,162]$. For instance, it has been observed that the telomerase-deficient $\mathrm{TERC}^{-/-}$mice with critically short telomeres, which possess dysfunctional bESCs showing a reduced ability to be mobilized out of their niche and an impaired capacity to regenerate the hair follicle and skin epidermis, were characterized by a premature skin-aging and death [98]. In fact, bESCs isolated from these telomerase-deficient mice exhibited a low proliferative capacity ex vivo [98]. Interestingly, the TERT re-introduction into late-generation telomerase-deficient $\mathrm{TERC}^{-/-}$ mice, however, could restore the telomerase activity and telomere length and prevent bESC defects and premature skin pathologies associated with aging and death of mice without increased the tumorigenesis $[98,163]$. In the same pathway, it has also been reported that the number and proliferative capacity of bESCs were decreased in Zmpste24-null progeroid mice, which display progeroid symptoms characterized by an aberrant nuclear envelope architecture due to nuclear lamina defects, as compared to Zmpste24 $4^{-/-} \mathrm{Lmna}^{+/-}$mutant mice [164]. It has also been noticed that Wnt and MITF were altered in dysfunctional bESCs and these immature cells and their supporting cells in the hair bulb region showed an enhanced rate of apoptotic death [164]. The $p 53^{+/ m}$ or $\Delta N p 63 \alpha$ mice, which display the pathological signs associated with premature skin aging-related phenotypes, were also characterized by a decreased expression level of nicotinamide adenine dinucleotide (NAD)-dependent deacytylase protein, sirtuin 1 (SIRT1, silent mating type information regulation 2 , homologue 1 ), and reduced longevity relative to wild-type animal [165]. Importantly, an inhibition or conditional ablation of Notch/Hes1, Bcl-2-dependent SCF/KIT and master regulator MITF signalling elements also caused a gradual and dramatic elimination of bulge-resident melanocyte stem/progenitor cells by apoptosis in animal model in vivo [21, $112,118-120,126,166]$. This progressive loss of melanocyte stem/progenitor cells and their mature progenies, the melaninproducing melanocytes in the bulb areas, was accompanied by a severe defect in hair pigmentation and an accelerated and intensive hair greying, the prototypical signs of skin aging (Fig. 1) 
[21, 118-120, 166]. Of particular interest, the hair greying phenotype and premature mice death by polycystic kidney disease observed for $\mathrm{Bcl}-2^{-1-}$ mice could be prevented by a simultaneous down-regulation of pro-apoptotic BH3-only $\mathrm{Bcl}-2$ family member, BIM suggesting that this factor may constitute a potential anti-aging therapeutic target [166].

In addition, certain lines of experimental evidence have also indicated that the activation of $\mathrm{p} 16^{\mathrm{INK} 4 \mathrm{~A}} / \mathrm{pRb}$ and/or $\mathrm{p} 53$ tumour suppressor-induced signalling pathways, which may lead to cellular senescence or apoptotic death, may contribute to counteract skin cancer development (Fig. 2) [28, 167-171]. As a matter of fact, the presence of functional p53 signalling pathway in $\mathrm{TERC}^{-/-}$ mice, which are deficient in telomerase, has been associated with an induction of senescence and apoptotic cell death and enhanced resistant to spontaneous skin tumorigenesis $[170,171]$. However, $\mathrm{TERC}^{-1-} \mathrm{p} 53^{\mathrm{R} 172 \mathrm{P}}$ mice, which are able to trigger the senescence via the $\mathrm{p} 53 / \mathrm{p} 21^{\mathrm{CIP1} / \mathrm{WAP} 1}$ cascade but not apoptosis were resistant to spontaneous skin tumorigenesis while skin carcinomas were induced by 7, 12-dimethylbenz[a]anthracene (DMBA) plus 12-0tetradecanoylphorbol-13-acetate (TPA) in these mice [171]. In fact, five out of seven chemically treated TERC ${ }^{-/-} p 53^{\mathrm{R} T 72 \mathrm{P}}$ mice developed highly proliferative pre-malignant lesions, squamous papillous/keratoacanthomas and four out of five mice displayed invasive SCCs despite a high staining of $\mathrm{p} 53 / \mathrm{p} 21^{\text {CIP1/WAP1 }}$ were detected in these malignant lesions [171]. In the same way, it has been observed that the K5TRF2 mice overexpressing telomere-binding factor 2 (TRF2) under control of the regulatory region of keratin 5 (K5) gene in the stem cell compartment of different epithelia including the skin, exhibited severe premature skin aging defects with increased age as compared to agematched wild-type mice [152, 172]. These skin defects of K5TRF2 mice include hair loss, skin hyperpigmentation and dryness and an increased predisposition to develop skin cancer after exposure to light [152, 172]. These skin defects, which resemble to the skin phenotypes observed in some human premature aging disorders such as XP syndrome, have been associated with a XPF nuclease-dependent telomere loss and increased chromosomal instability induced through an enhanced expression of TRF2 and p53 in bESCs leading to their dysfunction [152]. Importantly, p53 deletion in K5TRF2 mice model could rescue bESC defects in the absence of telomere elongation while these K5TRF2/p53-1- mice showed an accelerated onset of pre-neoplastic skin lesions and UV-induced skin carcinogenesis including BCCs and SCCs relative to K5TRF2, $p 53^{-1-}$ and/or wild-type mice used as controls [152].

Altogether, these observations suggest that the induction of cell cycle arrest and senescence mediated through the stimulation of tumour suppressor gene products such as p53 may be effective to decrease the incidence of only certain skin cancer subtypes. Moreover, the down-regulation of tumour suppressor gene products combined with an accumulation of numerous genetic and/or epigenetic alterations in skin-resident stem/progenitor cells during chronological aging or photoaging may also allow them to bypass the senescence and apoptotic cell death processes and culminate to skin cancer development.

\section{Altered functions of skin-resident adult stem/progenitor cells in skin hyperpro- liferative disorders and cancers}

The down-regulation of tumour suppressor gene products such as $\mathrm{p} 16^{\mathrm{INK} 4 \mathrm{~A}} / \mathrm{pRb}, \mathrm{p} 19^{\mathrm{ARF}} / \mathrm{p} 53 / \mathrm{p} 21^{\mathrm{WAPI} / \mathrm{CIPI}}$ and/or phosphatase and tensin homologue deleted on chromosome 10 (PTEN), deregulation of growth factor signalling cascades involved in the stringent regulation of proliferation, survival and/or differentiation of KSCs and bulge stem cells and photoaging represent important factors that contribute to development of diverse skin pathologies (Figs 1 and 2) [6, 51, 55, 83, 173-176]. Among them, there are the epidermal hyperproliferative disorders such as impaired wound healing and psoriasis, basaloid follicular hamartoma and skin cancers including BCCs, SCCs and melanoma. Particularly, a long-term skin exposure to UV radiations may cause inflammatory and immunosuppressive effects and DNA damages on sun-exposed areas of skin, and thereby result in major DNA mutations and photoproduct formation in skin cells promoting skin cancer initiation [25, 48-50, 52, 162 , 177]. For instance, a depletion of cellular antioxidant enzymes such as catalase and superoxide dismutase (SOD) induced through an UV light exposure may result in an enhanced reactive oxygen species (ROS) production and oxidative stress [25, 30]. These molecular events may cause severe damages to DNA, proteins, lipids and carbohydrates in skin cells, and thereby promote skin cancer development. In this matter, we are reporting frequent deregulation occurring in skin-resident adult stem/progenitor cells and their progenies which may be associated with the development of BCCs, SCCs or melanoma.

\section{Potential implications of cancer stem/progenitor cells in basal cell and squamous cell cancers}

Recent studies revealed that an extensive UV light exposureinduced DNA mutations and genetic and/or epigenetic alterations leading to a sustained activation of TERT, hedgehog, EGFR and/or Wnt/ $\beta$-catenin signalling pathways in skin-resident stem/progenitor cells and their progenies contribute to the development of certain cutaneous BCC and SCC subtypes [1, 49, $52,83,173,178]$. In this regard, accumulating lines of experimental evidence have indicated that certain subtypes of BCCs and SCCs could derive from the malignant transformation either of skin bESCs or their early progenies localized within or in close proximity to the bulge niche in hair follicles and/or skin cells in the basal layer of IFE $[44,47,56,57,175,179,180]$. More particularly, a sustained activation of sonic hedgehog pathway SHH/patched (PTCH)/GLI transcription factors, due to an overexpression of $\mathrm{SHH}$ ligand, activating mutations in smoothened (SMO) co-receptor or inactivating mutations in PTCH receptor as well as Wnt/ $\beta$-catenin cascade in skin cells has been associated with the etiopathogenesis of certain inherited or sporadic BCC 
subtypes in human [49, 102, 180-184]. Consistent with critical implication of hedgehog cascade in BCCs, it has been shown that an aberrant expression or activation of hedgehog signalling effectors, including the overexpression of SHH ligand, an activated human M2SM0 mutant or GLI-1 or 2, in skin stem/progenitor cells found in hair follicles and/or basal layer of epidermis in mice model in vivo resulted in the cell hyperproliferation and human BCC-like tumour development [56, 175, 185-192]. Moreover, it has been observed that the SOX9 transcription factor, which represents a potential downstream target of hedgehog pathway in hair follicle bESCs, was strongly expressed in cancer cells detected in BCCs [179]. The ablation of Notch1 receptor in mouse epidermis by using tissue-specific inducible gene-targeting approach also resulted in a sustained expression of GLI-2 concomitant with the development of epidermal hyperplasia followed by BCC-like tumours [193]. These data suggest then that Notch1 may act as a tumour-suppressor gene product in skin epidermis. In this matter, loss-of-function mutations in $\mathrm{PTCH}-1$ receptor or activating mutations in SMO resulting in a constitutive activation of hedgehog pathway, has also been associated with the development of rare diseases such as nevoid basal cell carcinoma syndrome (NBCCS) and accelerated aging disorder, XP, which are typically characterized by skin defects and a high BCC incidence [159-161, 183, 186, 194].

On the other hand, an increased expression of CK19, which is considered as a putative marker of bESCs, has also been observed in certain SCC tissue specimens [44]. Moreover, a small subpopulation of murine $\mathrm{CD}_{3} 4^{+}$cancer stem/progenitor cell population characterized by the phenotypic and functional properties like normal bESCs has been detected in early stage of SCCs [57]. The isolated fraction of $\mathrm{CD}^{+} 4^{+}$cancer stem/ progenitor cells were able to give rise to the tumours after transplantation in mice in vivo showing a hierarchical organization resembling primary malignant neoplasm [57]. The ablation of the $\beta$-catenin gene in these $\mathrm{CD} 34^{+}$cancer stem/progenitor cells resulted in their loss and a complete tumour regression suggesting a critical role of the activation of Wnt/ $\beta$-catenin cascade in triggering of certain SCC subtypes [57]. The transcriptional suppression of p53 induced-Notch gene expression through the activation of EGFR/c-Jun signalling in keratinocytes also led to a down-regulation of Notch1-initiated differentiation pathway and expansion of stem cell populations that promoted the development of SCCs $[82,83]$. In spite these advances, additional investigations are necessary to more precisely determine the specific implication of KSCs residing near the basement membrane in basal epithelial layer versus bESCs in the development of different BCC or SCC subtypes (Fig. 1).

\section{Potential implications of cancer stem/progenitor cells in melanoma}

A growing body of experimental evidence has also revealed that the cutaneous melanoma, which generally shows a high propen- sity to metastasize and resistance to current therapeutic treatments, could arise from cancer cells endowed with stem cell-like properties [58-63, 112, 195-198]. In support with this, small subpopulations of cancer stem/progenitor cells with stem cell-like properties have been identified and isolated from primary and secondary tumour specimens of patients with melanoma as well as human primary WM115 and metastatic WM239A and murine B16F10 melanoma cell lines [58-63, 65, 195, 196, 198]. These melanoma stem/progenitor cells expressed different biomarkers [CD133, CD44, CD20, telomerase reverse transcriptase (TERT), nestin, Nanog and/or ABC transporters such as MDR-1, ABCG2 and $A B C B 5]$. More specifically, it has been reported that a small subset of cancer stem/progenitor cells expressing MDR1/ABCB2/ABCB5/Nanog/TERT markers, which has been isolated from primary melanoma specimens, showed higher clonogenicity and self-renewal capacities in vitro than MDR-1 negative cancer cell fraction [62]. The ex vivo culture of a $\mathrm{CD}_{2} \mathrm{O}^{+}$cancer cell fraction enriched from melanoma cell lines and metastases in the growth medium, which is used for human embryonic stem cells, also resulted in their propagation under form of non-adherent spheres [59]. Each individual multipotent $\mathrm{CD}_{2} \mathrm{O}^{+}$cancer cell from melanoma spheres was able to differentiate like eNCSCs into multiple cell types showing the phenotypic features like the melanocytes, adipocytes, osteocytes and chondrocytes under well definite culture conditions [59]. Moreover, the $\mathrm{CD}_{133^{+}}$melanoma cells isolated from metastatic melanoma biopsies were also able to form melanocytic tumours in mice in vivo while the CD133 cancer cell fraction does not induce the melanoma formation [61]. In the same way, a small subpopulation of Cripto- $1^{+}$cells expressing elevated levels of 0 ct3/4, Nanog and MDR-1 stem celllike markers, which has been isolated from the metastatic melanoma cell line C8161, also displayed a slow growing and sphere forming capacity in vitro [199]. Another small side population (SP) expressing nestin and premelanosomal marker, gp100 has also been isolated by efflux Hoechst 33342 dye technique from metastatic melanoma DM1N, DM2N and DM3N cell lines which were originally established from lymph node melanoma metastases. It has been observed that these SP cells, which possessed a small size and were less melanized that other cell fraction, were able to give rise to differentiated melanoma cells. These SP cells also showed a high resistant to cytosine $\beta$-D-arabinofuranoside hydrochloride (Ara-C) treatment [64]. Hence, it appears that the primary and metastatic melanomas may arise from tumorigenic cancer cells with the stem cell-like properties. Particularly, the transition from skin-confined melanoma into invasive and metastatic melanocytic tumours usually implicates an accumulation of distinct oncogenic events in tumorigenic melanoma cells.

\section{Molecular events associated with melanoma progression}

The progression of primary melanoma into aggressive, invasive and metastatic melanocytic tumours is usually associated with a deregulation in numerous signalling elements. Among them, 
there are the alterations in tumour suppressing pathways including $\mathrm{p} 16^{\mathrm{INK} 4 \mathrm{~A}} /$ cyclin-dependent kinase 4 (CDK4)/pRb and $\mathrm{p} 19^{\mathrm{ARF}} / \mathrm{p} 53$ as well as the activation of multiple growth factor cascades such as hedgehog, Wnt, Notch, Nodal and diverse receptor tyrosine kinases (RTKs) such as EGF/EGFR, SCF/KIT and hepatocyte growth factor/scatter factor (HGF)/c-MET and activating mutations in KIT (Fig. 3) [46, 53, 66, 174, 200-204]. Particularly, inherited or somatic events including an inactivation of tumour suppressor genes such as p16 ${ }^{\text {INK4A }}$, p1 $19^{\mathrm{ARF}}, \mathrm{p} 53$ and PTEN and/or activating mutations in KIT, H-Ras, N-Ras or B-Raf (v-Raf murine sarcoma viral oncogene homologue B1) combined with a sustained activation of diverse signalling elements including Ras/ERK, $\mathrm{PI}_{3} \mathrm{~K} / \mathrm{Akt}$ and NF- $\mathrm{B}$ generally contribute to melanoma development (Figs 2 and 3) [55, 177, 201, 205-210]. For instance, the data from an investigation consisting of a 10-year follow-up period of 31 patients with melanoma have revealed that a decreased expression of $p R b, p 53$, $\mathrm{p} 21^{\mathrm{WAF} 1 / \mathrm{CIP} 1}, \mathrm{p} 27^{\mathrm{KIP} 1}$ and pro-apoptotic factors, Bax and Bak may be associated with a higher risk of melanoma metastases [55]. In support with critical functions of $\mathrm{p} 16^{\text {INK4A }}$ and $\mathrm{p} 19^{\mathrm{ARF}}$ protein loss and Ras activation in the development of aggressive metastatic melanomas, it has been observed that the

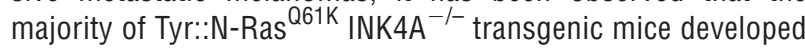
primary melanocytic and multifocal tumours that metastazed to lymph nodes, lung and liver [66]. The cancer cells expressing the stem cell-like marker, nestin isolated from primary melanoma specimen could also be subcutaneously transplanted in nude mice, and when intravenously injected into non-obese diabetic-severe combined immunodeficiency (NOD/SCID) mice, they metastazed at lung [66]. Interestingly, recent data have also revealed that the stem cell-like markers including CD133, CD44 and ABCB5 multidrug transporter, which are expressed by melanoma stem/progenitor cells, can contribute to their malignant behaviour, and thereby they could constitute the potential molecular therapeutic targets (Fig. 3) [63, 65, 195]. In this matter, it is worth mentioning that the phenotypic and functional features of melanoma stem/progenitor cells as well as the number of melanoma-initiating cells that are able to drive tumour development may vary during the disease progression and before and after treatment initiation. As a matter of fact, a high proportion of human melanoma cells isolated from patients with primary and metastatic melanomas and expressing different phenotypic markers were able to form tumours in highly immunocompromised mice models in vivo [211]. Therefore, future investigations are required to more precisely definite the gene expression profiles and functions of specific stem cell-like markers expressed by melanoma stem/progenitor cells versus their differentiated progenies in the primary and secondary melanocytic tumours during cancer etiology and progression. Particularly, it will be important to establish if melanoma-initiating cells may derive from the malignant transformation of bulge-resident stem/progenitor cells like eNCSCs, melanocyte stem cells and/or their early progenitors endowed with the stem cell-like properties. These studies should help to develop effec- tive multitargeted therapies for eradicating the total mass of melanoma-initiating cells and their progenies at early and late stages of disease.

Collectively, together these observations suggest a major implication of dysfunctions or loss of skin-resident adult stem/progenitor cells in the development of numerous age-related skin disorders and carcinogenesis. These studies support then the therapeutic interest to target these immature and dysfunctional cells to prevent or treat diverse skin disorders and aggressive skin cancers that may be promoted with the passage of time. In regard with this, we described new promising anti-aging and cancer therapeutic strategies consisting of stem cell-based therapies and molecular targeting of deregulated signalling elements in skin cancer-initiating cells to treat diverse age-associated skin diseases and cancers in human.

\section{Novel stem cell-based therapies}

\section{Novel anti-aging therapies}

\section{Modulation of aging process by calorie \\ restriction and pharmacological agents}

Numerous studies have revealed that a nutritious diet, also designated as calorie restriction, use of pharmacological agents including anti-inflammatory and antioxidant compounds and activators of protein deacetylases such as sirtuins (silent information regulators) may represent the potent therapeutic strategies for improving cell survival and treating diverse metabolic skin disorders [25, 31-34, 212-214]. In fact, calorie restriction or anti-aging skin cares with these agent types may influence the expression and/or activity of signalling elements known to be involved in inflammation, oxidative stress, senescence or apoptotic death of skin-resident adult stem/progenitor cells and their progenies during chronological aging [25, 31, 32]. More specifically, the use of activators of sirtuins, which act as NAD ${ }^{+}$-dependent protein deacetylases, may modulate the activity of key gene products including p53 and forkhead box 0 (FOXOs) family of transcription factors that are involved in the regulation of cellular metabolism, stress resistance, senescence and apoptosis. Thereby, the activators of sirtuins can promote the cell survival and lifespan extension [31, $32,215]$. For instance, the results from a study consisting in a topical application on the face and neck of a formulation containing $1 \%$ yeast Kluyveromyces biopeptides acting as a sirtuin 1 activator carried out with 33 women aged from 37 to 64 years, indicated that this anti-aging skin care significantly improved the hydration, firmness and pigment colour intensity of skin after 4 weeks of treatment [31]. Moreover, the application of this formulation enriched in yeast Kluyveromyces biopeptides, which increased the expression levels of nuclear longevity protein sirtuin 1 , also decreased the rate of senescence and apoptotic death induced by UVB exposure on ex vivo epidermal cell culture 
established from healthy human skin [31]. In the same way, the use of natural polyphenolic compound, resveratol (trans-3, 4', 5 -trihydroxystilbene) found in red wines and diverse plant species such as grapes, peanuts, berries and pines, as a skin care ingredient, has also been shown to induce the anti-inflammatory and antioxidant effects and enhance the sirtuin enzymatic activity [33-37, 216, 217]. More specifically, a topical application of resveratol may reduce cellular ROS levels and prevent the development of cutaneous disorders such as skin hyperplasia and cancers that may be caused by an UVB light exposure and metabolic stress during chronological aging [34, 36, 37, 216, 217]. Although the therapeutic interest to use resveratol in skin care preparations, it has been reported that this agent, in counterpart, can also potentiate certain types of UVA-induced DNA strand breaks and apoptotic death of immortalized HaCat human keratinocyte cell line in vitro [218]. On the other hand, the activation of residual hair bulge-resident melanocyte stem/progenitor cells and/or their early progenies also may constitute a potential strategy for recovery melanin-producing melanocytes in hair bulb areas and treatment of hypopigmentation disorders such as vitiligo and premature hair greying $[152,219]$. For instance, it has been shown that the topical application of purified placental sphingolipid induced an enhanced MITF expression and its target genes via the stimulation of p38 stress-signalling pathway that restored follicular melaninproducing melanocytes and hair re-pigmentation in vivo in C57BL/6J mouse model of age-onset hair greying [152].

Based on these observations, it appears to be important to more precisely establish the molecular mechanisms associated with the anti-aging effects induced by calorie restriction, sirtuin activators and resveratol on skin. Particularly, it will be essential to estimate their actions on the regenerative capacity and survival of skin-resident stem/progenitor cells and the maintenance of skin homeostasis versus their systemic toxicity and tumorigenic potential at long term. The optimization of the administration mode and therapeutic doses of these anti-aging agents seems also to be necessary before their use in safe conditions in human beings.

\section{Novel cell-replacement and gene therapies}

The in vivo stimulation of endogenous skin-resident adult stem/progenitor cells or use of ex vivo expanded adult stem/progenitor cells or their differentiated progenies represent promising strategies for replacing dysfunctional or lost skin aged cells or obtaining physiologic tissue-engineered human skin equivalents for skin grafting after intense injuries [2, 38-43, 78, 135, 220]. Several therapeutic strategies have been investigated for skin reconstructive surgery after intractable and severe wounds such as burns, deep skin injuries, infections and decubitus ulcers, including cell grafting with diverse biocompatible artificial materials and/or skin fragments [39, 40]. For instance, the use of skin stem/progenitor cells and their progenies engineering for expressing human TERT or telomere RNA component (TR) represents a therapy of great interest for treating the chronological or premature aging disorders such as Werner progenoid syndrome, Fanconi anaemia and chronic dysplastic anaemia which are associated with the defects in TERT and/or TR leading a replicative senescence of skin cells $[38,163]$. Consistently, it has been reported that the bulge-resident ESCs in telomerase-deficient mice showed an impaired proliferative capacity that led to a decreased skin and hair growth [163]. The telomerase re-introduction in these mice, however, reversed the functional defects associated with a decreased telomerase activity and telomere shortening and restored the long-term survival of mice without increase skin tumorigenesis [163].

In addition, several data have revealed the beneficial effects to incorporate the dermal cells or BM-derived stem/progenitor cells for cell-replacement therapy and skin tissue engineering [39, 41, $78,139]$. The incorporation of dermal sheath cells (DSCs) in skin equivalents that can secrete diverse cytokines including insulingrowth factor-binding protein-2 (IGFBP-2), has been shown to enhance the number of putative p63-expressing KSCs, and improve the epidermal regenerative capacity [78]. Moreover, the use of cultured autologous BM-derived mesenchymal cells plus artificial dermis composite graft may also improve mixed chimerism and vascularized skin graft survival, and thereby promote the recovery of diverse types of intractable dermatopathies and prevent graft rejection [39]. Similarly, the inclusion of ex vivo expanded circulating EPCs from an autologous source onto tissue-engineered human skin substitutes has also been shown to result in the formation of functional microvessels that improved the perfusion and survival of bioengineered tissues [40].

\section{Novel cancer therapies targeting skin cancer stem/progenitor cells and their microenvironment}

Since the skin stem/progenitor cells appear to provide critical functions in BCCs, SCCs and melanoma initiation, invasion and metastasis at distant sites, treatment resistance and disease relapse, several anti-cancer strategies have been designed to eradicate the total cancer cell mass including skin cancer-initiating cells and their differentiated progenies. Among the potential chemopreventive and therapeutic approaches, there are the use of natural dietary components, specific inhibitors of telomerase, EGFR, hedgehog, Wnt/ $\beta$-catenin, Notch, Nodal/Cripto, hyaluronan (HA)/CD44 and/or SDF-1/CXCR4 signalling cascades and histone deacetylase (HDAC)-inhibitors as well as the molecular targeting of anti-apoptotic factors such as Bcl-2 and ABC multidrug transporters (Fig. 3) [1, 83, 192, 202, 221-226]. The results of in vitro and in vivo studies have revealed a beneficial effect to target these deregulated signalling elements, alone or in combination therapies, to inhibit the growth, survival, invasion and/or metastasis of skin cancer cells (Fig. 3) [173, 175, 203, 227-231]. Based on the observations that the telomerase re-activation may contribute to cell immortalization and cancer development, including skin cancers, several anti-telomerase strategies have been designed to inhibit the telomerase activity in cancer cells, and prevent the tumour development [170, 223, 232-236]. Moreover, the natural dietary component, resveratol has been shown to act as a potent chemopreventive and chemotherapeutic agent against the 
chemically- and UVB-induced non-melanoma development by activating the apoptotic pathways of cell death in mice models of skin carcinogenesis [35, 36]. Numerous studies have also revealed the beneficial effects to target the hedgehog signalling pathway to inhibit the growth and induce the apoptosis of BCC cells without major toxicity on normal cells [47, 192, 224, 237-239]. Among the hedgehog signalling inhibitor, there are SMO antagonists including a small molecule CUR61414 and the plant-derived steroidal alkaloid, cyclopamine or modulators of sterol levels including $3 \beta$-hydroxysteroid (pro-)vitamin D3 and cholesterol synthesis inhibitors, statins (HMG-CoA reductase inhibitors) [47, 192, 224, 237-240]. Of particular interest, the data from a phase 1 clinical trial have also revealed that the treatment of BCC patients with a hedgehog inhibitor, may reverse the growth of the tumours in certain patients [241, 242]. Moreover, the inhibition of EGFR and Notch1 signalling using specific EGFR tyrosine kinase activity inhibitor, AG1478 and $\gamma$-secretase inhibitor, DAPT (N-[N-3, 5-difluorophenacetyl)-L-alanyl]-S-phenylglycine t-butyl ester) has also been reported to synergistically induce a substantial rate of apoptotic death of SCC cells [82].

In the case of melanoma, it has been shown that the use of dominant-negative EGFR, inhibitor of tyrosine kinase activity (TKI) of EGFR (gefitinib, AG1478 or PD153035) or KIT (imatinib mesylate) as well as the blockade of Wnt5/Frizzeld/protein kinase $C$, Notch and Nodal/Cripto-1 cascades induced the cytotoxic effect on melanoma cells [203, 206, 210, 231, 243-246]. The targeting of $\mathrm{HA} / \mathrm{CD} 44$ tumorigenic pathway using mAb or soluble CD44 protein form also diminished the human melanoma growth and/or incidence of metastases in vitro and in mice models in vivo (Fig. 3) [230, 247-249]. The pharmacologic suppression of MITF transcription factor expression, which provides critical role in the regulation of differentiation and survival of melanocytic cell lineage through a topical application of HDAC inhibitor also reduced the skin pigmentation and melanoma formation in mouse xenografts derived melanoma cells in vivo [250]. Importantly, the molecular targeting of sonic hedgehog SHH/PTCH/GLI by using smoothened co-receptor inhibitor, cyclopamine also prevented the growth, recurrence, and metastasis of melanoma xenografts in mice in vivo suggesting that the melanoma-initiating cells may be eliminated following this treatment type [226]. In this same way, the downregulation of CD133 pentaspan transmembrane glycoprotein (prominin-1) in FEMX-I melanoma cells by short hairpin RNAs was also accompanied by a reduction of cell growth, cell motility, and capacity of cancer cells to form spheroids in vitro [65]. Moreover, the use of $\mathrm{mAb}$ directed against epitope 1 (AC133 and W6B3C1) or epitope 2 (AC141) of the CD133 protein, induced the cytotoxic effects in FEMX-I cells in vitro and markedly decreased their metastatic capacity in mice model in vivo (Fig. 3) [65]. The data from microarray analysis have also revealed that several gene products coding for Wnt inhibitors were up-regulated in the CD133 down-regulated cells [65]. These observations suggest then that the signalling pathway initiated through the CD133 stem cell-like marker can also contribute to malignant phenotype of melanoma stem cells in cooperation with Wnt cascade, and thereby constitute a potential molecular therapeutic target to eradicate the melanoma-initiating cells. Similarly, it has been reported that the use of a mAb directed against $A B C B 5$ efflux pump also inhibited the tumour growth of $\mathrm{CD} 33^{+} / \mathrm{ABCB}^{+}$melanoma stem cell-derived xenografts in vivo [63]. The ABCB5 blockade in the $\mathrm{CD}_{133^{+}} / \mathrm{ABCB}^{+}$melanoma stem cell subpopulation was accompanied by an intracellular doxorubicin accumulation that significantly restored drug sensitivity [58]. Additional characterization of the dose-responses and selectivity of these mAbs on melanoma stem/progenitor cells versus the normal adult stem cells expressing $\mathrm{CD}_{13} 3^{+} / \mathrm{ABCB}^{+}$in vitro and animal models in vivo is however required before their potential testing in clinical settings in safe conditions.

Other potential therapeutic strategies against invasive, metastatic and/or relapsed melanomas also include the immunotherapy-based melanoma vaccines, chemoimmunotherapies with immunosuppressive agents such as interferon- $\alpha$, gene therapy and anti-angiogenic therapy by using thalidomine, angiostatin and/or endostatin, without or plus a stem cell-based transplant [112, 221, 227, 251-255]. More particularly, it has been reported that the melanoma stem cells, including $\mathrm{CD}_{133^{+}}$clonogenic melanoma cells, express a significant level of cancer testis antigens (CTAs) suggesting that they could be efficiently targeted in vivo by CTA-directed immunotherapy $[253,255]$. A therapeutic regimen consisting to 5 -fluorocytosine plus engineered neural stem cells (NSCs) expressing cytosine deaminase, which acts as a pro-drug activating enzyme, also resulted in a significant reduction in the tumour border in animal models with established melanoma brain metastasis in vivo [254].

\section{Conclusions and future directions}

Altogether, these recent advancements made in the field of skinresident adult stem/progenitor cell biology have provided important information on the deregulated signalling cascades that may contribute to induce their dysfunctions, loss or malignant transformation during the chronological and accelerated aging and their pathological consequences. Additional studies are however necessary to more precisely establish the differentiallyexpressed gene products in these immature cells versus their differentiated progenies as well as the changes in their microenvironment occurring during human aging process. These future investigations should shed light onto intrinsic and extrinsic factors that may contribute to the progressive decline in regenerative capacity or loss of skin-resident adult stem/progenitor cells, and thereby help to develop new anti-aging strategies for preventing or delaying the onset of age-related skin disorders in human beings.

Further identification of specific biomarkers and drug targets in skin cancer stem/progenitor cells is also essential to more precisely establish their hierarchical organization and phenotypic features associated with the skin tumour development and progression from localized cancers in invasive and metastatic stages. In this regard, the establishment of specific functions of CD133 
protein in normal bulge stem/progenitor cells and melanoma stem/progenitor cells is of immense interest to identify the copartners that could be selectively targeted in highly tumorigenic and metastatic melanoma stem cells and without toxicity on normal $\mathrm{CD}_{133^{+}}$regenerative stem/progenitor cells found in skin and other tissues. These additional studies should lead to identification of novel drug targets for eradicating skin tumour- and metastasisinitiating cells, and thereby improving the clinical treatments against aggressive and recurrent skin cancers, and more particularly metastatic melanoma, which remain lethal with current therapeutic regimen options.

\section{Acknowledgements}

We are supported by grants from the National Institutes of Health (CA78590, CA111294, CA133774 and CA131944). We thank Ms. Kristi L. Berger for editing the manuscript.

\section{References}

1. Mimeault M, Bonenfant D, Batra SK. New advances on the functions of epidermal growth factor receptor and ceramides in skin cell differentiation, disorders and cancers. Skin Pharmacol Physiol. 2004; 17: 153-6.

2. Mimeault M, Batra SK. Recent advances on the significance of stem cells in tissue regeneration and cancer therapies. Stem Cells. 2006; 24: 2319-45.

3. McCullough JL, Kelly KM. Prevention and treatment of skin aging. Ann NY Acad Sci. 2006; 1067: 323-31.

4. Benitah SA. Epidermal stem cells in skin homeostasis and cutaneous carcinomas. Clin Transl Oncol. 2007; 9: 760-6.

5. Zouboulis CC, Baron JM, Bohm M, et al. Frontiers in sebaceous gland biology and pathology. Exp Dermatol. 2008; 17: 542-51.

6. Muller EJ, Williamson L, Kolly C, et al. Outside-in signaling through integrins and cadherins: a central mechanism to control epidermal growth and differentiation? $J$ Invest Dermatol. 2008; 128: 501-16.

7. Fuchs E. Skin stem cells: rising to the surface. J Cell Biol. 2008; 180: 273-84.

8. Fuchs $\mathrm{E}$, Horsley V. More than one way to skin. Genes Dev. 2008; 22: 976-85.

9. Tumbar T, Guasch G, Greco V, et al. Defining the epithelial stem cell niche in skin. Science. 2004; 303: 359-63.

10. Webb A, Li A, Kaur P. Location and phenotype of human adult keratinocyte stem cells of the skin. Differentiation. 2004; 72 : 387-95.

11. Larderet G, Fortunel NO, Vaigot $P$, et al. Human side population keratinocytes exhibit long-term proliferative potential and a specific gene expression profile and can form a pluristratified epidermis. Stem Cells. 2006; 24: 965-74.

12. Blanpain C, Lowry WE, Geoghegan A, et al. Self-renewal, multipotency, and the existence of two cell populations within an epithelial stem cell niche. Cell. 2004; 118: 635-48.

13. Blanpain C, Fuchs E. Epidermal stem cells of the skin. Annu Rev Cell Dev Biol. 2006; 22: 339-73.

14. Ito M, Liu Y, Yang Z, et al. Stem cells in the hair follicle bulge contribute to wound repair but not to homeostasis of the epidermis. Nat Med. 2005; 11: 1351-4.

15. Levy V, Lindon C, Zheng $Y$, et al. Epidermal stem cells arise from the hair follicle after wounding. FASEB J. 2007; 21: 1358-66.

16. Li L, Xie T. Stem cell niche: Structure and function. Annu Rev Cell Dev Biol. 2005; 21: 605-31.

17. Horsley V, O'Carroll D, Tooze R, et al. Blimp1 defines a progenitor population that governs cellular input to the sebaceous gland. Cell. 2006; 126: 597-609.

18. Nishimura EK, Jordan SA, Oshima H, et al. Dominant role of the niche in melanocyte stem-cell fate determination. Nature. 2002; 416: 854-60.

19. Sieber-Blum M, Grim M, Hu YF, et al. Pluripotent neural crest stem cells in the adult hair follicle. Dev Dyn. 2004; 231: 258-69.

20. Yu H, Fang D, Kumar SM, et al. Isolation of a novel population of multipotent adult stem cells from human hair follicles. Am J Pathol. 2006; 168: 1879-88.

21. Nishimura EK, Granter SR, Fisher DE. Mechanisms of hair graying: incomplete melanocyte stem cell maintenance in the niche. Science. 2005; 307: 720-4.

22. Benitah SA, Frye M, Glogauer M, et al. Stem cell depletion through epidermal deletion of Rac1. Science. 2005; 309: 933-5.

23. Sharpless NE, DePinho RA. How stem cells age and why this makes us grow old. Nat Rev Mol Cell Biol. 2007; 8: 703-13.

24. Youn SW, Kim DS, Cho HJ, et al. Cellular senescence induced loss of stem cell pro- portion in the skin in vitro. J Dermatol Sci. 2004; 35: 113-23.

25. Pillai S, Oresajo C, Hayward J, et al. Ultraviolet radiation and skin aging: roles of reactive oxygen species, inflammation and protease activation, and strategies for prevention of inflammation-induced matrix degradation - a review. Int J Cosmet Sci. 2005; 27: 17-34.

26. Roh C, Lyle $\mathbf{S}$. Cutaneous stem cells and wound healing. Pediatr Res. 2006; 59: 100R-3R.

27. Kwon OS, Yoo HG, Han JH, et al. Photoaging-associated changes in epidermal proliferative cell fractions in vivo. Arch Dermatol Res. 2008; 300: 47-52.

28. Mimeault M, Batra S.K. Recent insights into the molecular mechanisms involved in aging and the malignant transformation of adult stem/progenitor cells and their therapeutic implications. Aging Res Rev. 2009; 8: 94-112.

29. Chen W, Kang J, Xia J, et al. p53-related apoptosis resistance and tumor suppression activity in UVB-induced premature senescent human skin fibroblasts. Int $\mathrm{J}$ Mol Med. 2008; 21: 645-53.

30. Briganti S, Wlaschek M, Hinrichs C, et al. Small molecular antioxidants effectively protect from PUVA-induced oxidative stress responses underlying fibroblast senescence and photoaging. Free Radic Biol Med. 2008; 45: 636-44.

31. Moreau M, Neveu M, Stephan S, et al. Enhancing cell longevity for cosmetic application: a complementary approach. J Drugs Dermatol. 2007; 6: S14-9.

32. Lavu $\mathrm{S}$, Boss $\mathbf{0}$, Elliott $\mathrm{PJ}$, et al. Sirtuins-novel therapeutic targets to treat age-associated diseases. Nat Rev Drug Discov. 2008; 7: 841-53.

33. Ingram DK, Zhu M, Mamczarz J, et al. Calorie restriction mimetics: an emerging research field. Aging Cell. 2006; 5: 97-108. 
34. Neugebauer RC, Sippl W, Jung M. Inhibitors of NAD+ dependent histone deacetylases (sirtuins). Curr Pharm Des. 2008; 14: 562-73.

35. Baur JA, Sinclair DA. Therapeutic potential of resveratrol: the in vivo evidence. Nat Rev Drug Discov. 2006; 5: 493-506.

36. Athar $\mathrm{M}$, Back $\mathrm{JH}$, Tang $\mathrm{X}$, et al. Resveratrol: a review of preclinical studies for human cancer prevention. Toxicol Appl Pharmacol. 2007; 224: 274-83.

37. Baxter RA. Anti-aging properties of resveratrol: review and report of a potent new antioxidant skin care formulation. $J$ Cosmet Dermatol. 2008; 7: 2-7.

38. Shay JW, Wright WE. Use of telomerase to create bioengineered tissues. Ann NY Acad Sci. 2005; 1057: 479-91.

39. Yoshikawa T, Mitsuno H, Nonaka I, et al. Wound therapy by marrow mesenchymal cell transplantation. Plast Reconstr Surg. 2008; 121: 860-77.

40. Kung EF, Wang F, Schechner JS. In vivo perfusion of human skin substitutes with microvessels formed by adult circulating endothelial progenitor cells. Dermatol Surg. 2008; 34: 137-46.

41. Zhang CP, Fu XB. Therapeutic potential of stem cells in skin repair and regeneration. Chin J Traumatol. 2008; 11: 209-21.

42. Park BS, Jang KA, Sung JH, et al. Adipose-derived stem cells and their secretory factors as a promising therapy for skin aging. Dermatol Surg. 2008; 34: 1323-6.

43. Branski LK, Gauglitz GG, Herndon DN, et al. A review of gene and stem cell therapy in cutaneous wound healing. Burns. 2008; 35: 171-80.

44. Chen S, Takahara M, Kido M, et al. Increased expression of an epidermal stem cell marker, cytokeratin 19, in cutaneous squamous cell carcinoma. Br J Dermatol. 2008; 159: 952-5.

45. Lupi $\mathbf{0}$. Correlations between the Sonic Hedgehog pathway and basal cell carcinoma. Int J Dermatol. 2007; 46: 1113-7.

46. Bachmann IM, Puntervoll HE, Otte AP, et al. Loss of BMI-1 expression is associated with clinical progress of malignant melanoma. Mod Pathol. 2008; 21: 583-90.

47. Athar M, Tang X, Lee JL, et al. Hedgehog signalling in skin development and cancer. Exp Dermatol. 2006; 15: 667-77.

48. Erb P, Ji J, Kump E, et al. Apoptosis and pathogenesis of melanoma and nonmelanoma skin cancer. Adv Exp Med Biol. 2008; 624: 283-95.

49. Rass K, Reichrath J. UV damage and DNA repair in malignant melanoma and non- melanoma skin cancer. Adv Exp Med Biol. 2008; 624: 162-78.

50. Hussein MR. Ultraviolet radiation and skin cancer: molecular mechanisms. J Cutan Pathol. 2005; 32: 191-205.

51. Pons M, Quintanilla M. Molecular biology of malignant melanoma and other cutaneous tumors. Clin Transl Oncol. 2006; 8: 466-74.

52. Pacifico A, Goldberg LH, Peris K, et al. Loss of CDKN2A and p14ARF expression occurs frequently in human nonmelanoma skin cancers. Br J Dermatol. 2008; 158 : 291-7.

53. Liu ZJ, Xiao M, Balint K, et al. Notch1 signaling promotes primary melanoma progression by activating mitogen-activated protein kinase/phosphatidylinositol 3-kinase-Akt pathways and up-regulating $\mathrm{N}$-cadherin expression. Cancer Res. 2006; 66: 4182-90.

54. Chin L. The genetics of malignant melanoma: lessons from mouse and man. Nat Rev Cancer. 2003; 3: 559-70.

55. Tchernev G, Orfanos CE. Downregulation of cell cycle modulators p21, p27, p53, Rb and proapoptotic Bcl-2-related proteins Bax and Bak in cutaneous melanoma is associated with worse patient prognosis: preliminary findings. J Cutan Pathol. 2007; 34: $247-56$

56. Hutchin ME, Kariapper MS, Grachtchouk M, et al. Sustained Hedgehog signaling is required for basal cell carcinoma proliferation and survival: conditional skin tumorigenesis recapitulates the hair growth cycle. Genes Dev. 2005; 19: 214-23.

57. Malanchi I, Peinado H, Kassen D, et al. Cutaneous cancer stem cell maintenance is dependent on beta-catenin signalling. Nature. 2008; 452: 650-3.

58. Frank NY, Margaryan A, Huang $Y$, et al. ABCB5-mediated doxorubicin transport and chemoresistance in human malignant melanoma. Cancer Res. 2005; 65: 4320-33.

59. Fang D, Nguyen TK, Leishear K, et al. A tumorigenic subpopulation with stem cell properties in melanomas. Cancer Res. 2005; 65: 9328-37.

60. Dou J, Pan M, Wen P, et al. Isolation and identification of cancer stem-like cells from murine melanoma cell lines. Cell Mol Immunol. 2007; 4: 467-2.

61. Monzani E, Facchetti F, Galmozzi E, et al. Melanoma contains CD133 and ABCG2 positive cells with enhanced tumourigenic potential. Eur J Cancer. 2007; 43: 935-46.

62. Keshet GI, Goldstein I, Itzhaki $\mathbf{0}$, et al. MDR1 expression identifies human melanoma stem cells. Biochem Biophys Res Commun. 2008; 368: 930-6.

63. Schatton T, Murphy GF, Frank NY, et al. Identification of cells initiating human melanomas. Nature. 2008; 451: 345-9.

64. Grichnik JM, Burch JA, Schulteis RD et al. Melanoma, a tumor based on a mutant stem cell? J Invest Dermatol. 2006; 126: 142-53.

65. Rappa G, Fodstad 0, Lorico A. The stem cell-associated antigen CD133 (Prominin1) is a molecular therapeutic target for metastatic melanoma. Stem Cells. 2008; 26: 3008-17.

66. Ackermann J, Frutschi M, Kaloulis K, et al. Metastasizing melanoma formation caused by expression of activated $\mathrm{N}$ RasQ61K on an INK4a-deficient background. Cancer Res. 2005; 65: 4005-11.

67. Lacina L, Dvorankova B, Smetana K, et al. Marker profiling of normal keratinocytes identifies the stroma from squamous cell carcinoma of the oral cavity as a modulatory microenvironment in co-culture. Int J Radiat Biol. 2007; 83: 837-48.

68. Marsh D, Dickinson S, Neill GW, et al. alpha vbeta 6 Integrin promotes the invasion of morphoeic basal cell carcinoma through stromal modulation. Cancer Res. 2008; 68: 3295-303.

69. Ruiter D, Bogenrieder T, Elder D, et al. Melanoma-stroma interactions: structural and functional aspects. Lancet Oncol. 2002; 3: 35-43.

70. Watt FM. Role of integrins in regulating epidermal adhesion, growth and differentiation. EMBO J. 2002; 21: 3919-26.

71. Kloepper JE, Tiede S, Brinckmann J, et al. Immunophenotyping of the human bulge region: the quest to define useful in situ markers for human epithelial hair follicle stem cells and their niche. Exp Dermatol. 2008; 17: 592-609.

72. Kamstrup M, Faurschou A, Gniadecki R, et al. Epidermal stem cells - role in normal, wounded and pathological psoriatic and cancer skin. Curr Stem Cell Res Ther. 2008; 3: 146-50.

73. Pellegrini G, Dellambra E, Golisano $\mathbf{0}$, et al. p63 identifies keratinocyte stem cells. Proc Natl Acad Sci USA. 2001; 98: 3156-61.

74. Jost M, Kari C, Rodeck U. The EGF receptor - an essential regulator of multiple epidermal functions. Eur J Dermatol. 2000; 10: $505-10$.

75. Jensen KB, Watt FM. Single-cell expression profiling of human epidermal stem and transit-amplifying cells: Lrig1 is a reg- 
ulator of stem cell quiescence. Proc Natl Acad Sci USA. 2006; 103: 11958-63.

76. Nguyen BC, Lefort K, Mandinova A, et al. Cross-regulation between Notch and p63 in keratinocyte commitment to differentiation. Genes Dev. 2006; 20: 1028-42.

77. Devgan V, Nguyen $\mathrm{BC}, \mathrm{Oh} \mathrm{H}$, et al. p21WAF1/Cip1 suppresses keratinocyte differentiation independently of the cell cycle through transcriptional up-regulation of the IGF-I gene. J Biol Chem. 2006; 281: 30463-70.

78. Kim DS, Cho HJ, Yang SK, et al. IGFBP-2 Contributes to the proliferation of less proliferative cells in forming skin equivalents. Tissue Eng Part A. 2009; 15: 1075-80.

79. Okuyama R, Ogawa E, Nagoshi H, et al. p53 homologue, p51/p63, maintains the immaturity of keratinocyte stem cells by inhibiting Notch1 activity. Oncogene. 2007; 27: 848-56.

80. Lechler T, Fuchs E. Asymmetric cell divisions promote stratification and differentiation of mammalian skin. Nature. 2005; 437: 275-80.

81. Okuyama R, Lefort K, Dotto GP. A dynamic model of keratinocyte stem cell renewal and differentiation: role of the p21WAF1/Cip1 and Notch1 signaling pathways. J Investig Dermatol Symp Proc. 2004; 9: 248-52.

82. Lefort K, Mandinova A, Ostano $\mathrm{P}$, et al. Notch1 is a p53 target gene involved in human keratinocyte tumor suppression through negative regulation of ROCK $1 / 2$ and MRCKalpha kinases. Genes Dev. 2007; 21: 562-77.

83. Kolev V, Mandinova A, Guinea-Viniegra $\mathrm{J}$, et al. EGFR signalling as a negative regulator of Notch1 gene transcription and function in proliferating keratinocytes and cancer. Nat Cell Biol. 2008; 10: 902-11.

84. Takeda K, Takeuchi $\mathbf{0}$, Tsujimura T, et al. Limb and skin abnormalities in mice lacking IKKalpha. Science. 1999; 284: 313-6.

85. Li Q, Lu Q, Estepa G, Verma IM. Identification of 14-3-3sigma mutation causing cutaneous abnormality in repeated-epilation mutant mouse. Proc Natl Acad Sci USA. 2005; 102: 15977-82.

86. Richardson RJ, Dixon J, Malhotra S, et al. Irf6 is a key determinant of the keratinocyte proliferation-differentiation switch. Nat Genet. 2006; 38: 1329-34.

87. Ingraham CR, Kinoshita A, Kondo S, et al. Abnormal skin, limb and craniofacial morphogenesis in mice deficient for interferon regulatory factor 6 (Irf6). Nat Genet. 2006; 38: 1335-40.
88. Zhu F, Xia X, Liu B, et al. IKKalpha shields 14-3-3sigma, a G(2)/M cell cycle checkpoint gene, from hypermethylation, preventing its silencing. Mol Cell. 2007; 27: 214-27.

89. Liu B, Xia X, Zhu F, et al. IKKalpha is required to maintain skin homeostasis and prevent skin cancer. Cancer Cell. 2008; 14: 212-25.

90. Lyle S, Christofidou-Solomidou M, Liu Y, et al. The C8/144B monoclonal antibody recognizes cytokeratin 15 and defines the location of human hair follicle stem cells. J Cell Sci. 1998; 111 (Pt 21): 317988.

91. Roh C, Tao Q, Photopoulos C, et al. In vitro differences between keratinocyte stem cells and transit-amplifying cells of the human hair follicle. J Invest Dermatol. 2005; 125: 1099-105.

92. Levy V, Lindon C, Harfe BD, et al. Distinct stem cell populations regenerate the follicle and interfollicular epidermis. Dev Cell. 2005; 9: 855-61.

93. Ito M, Yang Z, Andl T, et al. Wnt-dependent de novo hair follicle regeneration in adult mouse skin after wounding. Nature. 2007; 447: 316-20.

94. Trempus CS, Morris RJ, Bortner CD, et al. Enrichment for living murine keratinocytes from the hair follicle bulge with the cell surface marker CD34. J Invest Dermatol. 2003; 120: 501-11.

95. Ohyama M, Terunuma A, Tock CL, et al. Characterization and isolation of stem cellenriched human hair follicle bulge cells. $J$ Clin Invest. 2006; 116: 249-60.

96. Lee S-H, Chung M-K, Sohn Y-J, et al. Human hair follicle cells with the cell surface marker CD34 can regenerate new mouse hair follicles and located in the outer root sheath of immunodeficient nude mice. Int J of Stem cells. 2009; 1: 70-81.

97. Flores I, Canela A, Vera E, et al. The longest telomeres: a general signature of adult stem cell compartments. Genes Dev. 2008; 22: 654-67.

98. Flores I, Cayuela ML, Blasco MA. Effects of telomerase and telomere length on epidermal stem cell behavior. Science. 2005; 309: 1253-6.

99. Sarin KY, Cheung P, Gilison D, et al. Conditional telomerase induction causes proliferation of hair follicle stem cells. Nature. 2005; 436: 1048-52.

100. Choi J, Southworth LK, Sarin KY, et al. TERT promotes epithelial proliferation through transcriptional control of a Mycand Wnt-related developmental program. PLoS Genet. 2008; 4: e10.
101. Rajaraman S, Choi J, Cheung $\mathbf{P}$, et al. Telomere uncapping in progenitor cells with critical telomere shortening is coupled to S-phase progression in vivo. Proc Natl Acad Sci USA. 2007; 104: 17747-52.

102. Ghali L, Wong ST, Green J, et al. Gli1 protein is expressed in basal cell carcinomas, outer root sheath keratinocytes and a subpopulation of mesenchymal cells in normal human skin. $J$ Invest Dermatol. 1999; 113: 595-9.

103. Huelsken J, Vogel R, Erdmann B, et al. beta-Catenin controls hair follicle morphogenesis and stem cell differentiation in the skin. Cell. 2001; 105: 533-45.

104. Yamamoto N, Tanigaki $\mathrm{K}$, Han $\mathrm{H}$, et al. Notch/RBP-J signaling regulates epidermis/hair fate determination of hair follicular stem cells. Curr Biol. 2003; 13: 333-8.

105. Vidal VP, Chaboissier MC, Lutzkendorf $S$, et al. Sox9 is essential for outer root sheath differentiation and the formation of the hair stem cell compartment. Curr Biol. 2005; 15: 1340-51.

106. Kasper M, Schnidar H, Neill GW, et al. Selective modulation of Hedgehog/GLI target gene expression by epidermal growth factor signaling in human keratinocytes. Mol Cell Biol. 2006; 26: 6283-98.

107. Gat U, DasGupta R, Degenstein L, et al. De Novo hair follicle morphogenesis and hair tumors in mice expressing a truncated beta-catenin in skin. Cell. 1998; 95: 605-14.

108. Zhang $\mathrm{Y}$, Andl $\mathrm{T}$, Yang $\mathrm{SH}$, et al. Activation of beta-catenin signaling programs embryonic epidermis to hair follicle fate. Development. 2008; 135: 2161-72.

109. Estrach S, Ambler CA, Lo CC, et al. Jagged 1 is a beta-catenin target gene required for ectopic hair follicle formation in adult epidermis. Development. 2006; 133: 4427-38.

110. Demehri S, Kopan R. Notch signaling in bulge stem cells is not required for selection of hair follicle fate. Development. 2009; 136: 891-6.

111. Osawa M, Egawa G, Mak SS, et al. Molecular characterization of melanocyte stem cells in their niche. Development. 2005; 132: 5589-99.

112. Chin L, Garraway LA, Fisher DE. Malignant melanoma: genetics and therapeutics in the genomic era. Genes Dev. 2006; 20: 2149-82.

113. Grichnik JM. Melanoma, nevogenesis, and stem cell biology. J Invest Dermatol. 2008; 128: $2365-80$. 
114. Na GY, Paek SH, Park BC, et al. Isolation and characterization of outer root sheath melanocytes of human hair follicles. $\mathrm{Br} \mathrm{J}$ Dermatol. 2006; 155: 902-9.

115. Nishikawa S, Osawa M. Generating quiescent stem cells. Pigment Cell Res. 2007; 20: 263-70.

116. Mak SS, Moriyama M, Nishioka $\mathrm{E}$, et al. Indispensable role of $\mathrm{Bcl} 2$ in the development of the melanocyte stem cell. Dev Biol. 2006; 291: 144-53.

117. Aubin-Houzelstein G, Djian-Zaouche J, Bernex F, et al. Melanoblasts' proper location and timed differentiation depend on Notch/RBP-J signaling in postnatal hair follicles. J Invest Dermatol. 2008; 128: 2686-95.

118. Kumano K, Masuda S, Sata M, et al. Both Notch1 and Notch2 contribute to the regulation of melanocyte homeostasis. Pigment Cell Melanoma Res. 2008; 21: 70-8.

119. Schouwey K, Delmas V, Larue L, et al. Notch1 and Notch2 receptors influence progressive hair graying in a dose-dependent manner. Dev Dyn. 2007; 236: 282-9.

120. Moriyama M, Osawa M, Mak SS, et al. Notch signaling via Hes1 transcription factor maintains survival of melanoblasts and melanocyte stem cells. J Cell Biol. 2006; 173: 333-9.

121. Belmadani $\mathbf{A}$, Jung $\mathbf{H}$, Ren $\mathbf{D}$, et al. The chemokine SDF-1/CXCL12 regulates the migration of melanocyte progenitors in mouse hair follicles. Differentiation. 2009; 77: 395-411.

122. Yang G, Li Y, Nishimura EK, et al. Inhibition of PAX3 by TGF-beta modulates melanocyte viability. Mol Cell. 2008; 32 : 554-63.

123. Jeon S, Kim NH, Kim JY, et al. Stem cell factor induces ERM proteins phosphorylation through PI3K activation to mediate melanocyte proliferation and migration. Pigment Cell Melanoma Res. 2009; 22 : 77-85.

124. Sieber-Blum M, Grim M. The adult hair follicle: cradle for pluripotent neural crest stem cells. Birth Defects Res C Embryo Today. 2004; 72: 162-72.

125. Hu YF, Zhang ZJ, Sieber-Blum M. An epidermal neural crest stem cell (EPI-NCSC) molecular signature. Stem Cells. 2006; 24: 2692-702.

126. Yoshida H, Kunisada T, Grimm T, et al. Review: melanocyte migration and survival controlled by SCF/c-kit expression. J Investig Dermatol Symp Proc. 2001; 6: 1-5.

127. Schouwey K, Beermann F. The Notch pathway: hair graying and pigment cell homeostasis. Histol Histopathol. 2008; 23 : 609-19.

128. Rendl M, Lewis L, Fuchs E. Molecular Dissection of Mesenchymal-Epithelial Interactions in the Hair Follicle. PLOS Biol. 2005; 3: 1910-24.

129. Kawase $Y$, Yanagi $Y$, Takato $T$, et al. Characterization of multipotent adult stem cells from the skin: transforming growth factor-beta (TGF-beta) facilitates cell growth. Exp Cell Res. 2004; 295: 194-203.

130. Fernandes KJ, McKenzie IA Mill P, et al. A dermal niche for multipotent adult skinderived precursor cells. Nat Cell Biol. 2004; 6: 1082-93.

131. Amoh Y, Li L, Campillo $R$, et al. Implanted hair follicle stem cells form Schwann cells that support repair of severed peripheral nerves. Proc Natl Acad Sci USA. 2005; 102: 17734-8.

132. Wong CE, Paratore C, DoursZimmermann MT, et al. Neural crestderived cells with stem cell features can be traced back to multiple lineages in the adult skin. J Cell Biol. 2006; 175: 1005-15.

133. Toma JG, Akhavan M, Fernandes KJ, et al. Isolation of multipotent adult stem cells from the dermis of mammalian skin. Nat Cell Biol. 2001; 3: 778-84.

134. Belicchi M, Pisati F, Lopa R, et al. Human skin-derived stem cells migrate throughout forebrain and differentiate into astrocytes after injection into adult mouse brain. J Neurosci Res. 2004; 77: 475-86.

135. Mimeault M, Hauke R, Batra SK. Stem cells - A revolution in therapeutics-Recent advances on the stem cell biology and their therapeutic applications in regenerative medicine and cancer therapies. Clin Pharmacol Ther. 2007; 82: 252-64.

136. Lorenz K, Sicker M, Schmelzer E, et al. Multilineage differentiation potential of human dermal skin-derived fibroblasts. Exp Dermatol. 2008; 17: 925-32.

137. Zengin E, Chalajour F, Gehling UM, et al. Vascular wall resident progenitor cells: a source for postnatal vasculogenesis. Development. 2006; 133: 1543-51.

138. Asahara T, Kawamoto A. Endothelial progenitor cells for postnatal vasculogenesis. Am J Physiol Cell Physiol. 2004; 287: C572-9.

139. Wu Y, Wang J, Scott PG, et al. Bone marrow-derived stem cells in wound healing: a review. Wound Repair Regen. 2007; 15: S18-26.

140. Fisher GJ, Varani J, Voorhees JJ. Looking older: fibroblast collapse and therapeutic implications. Arch Dermatol. 2008; 144: 666-72.
141. Hayward NK. Genetics of melanoma predisposition. Oncogene. 2003; 22: 3053-62.

142. Varani J, Dame MK, Rittie L, et al. Decreased collagen production in chronologically aged skin: roles of age-dependent alteration in fibroblast function and defective mechanical stimulation. Am J Pathol. 2006; 168: 1861-8.

143. Kang J, Chen W, Xia J, et al. Extracellular matrix secreted by senescent fibroblasts induced by UVB promotes cell proliferation in HaCaT cells through PI3K/AKT and ERK signaling pathways. Int J Mol Med. 2008; 21: 777-84.

144. Borlon C, Vankoningsloo S, Godard P, et al. Identification of p53-dependent genes potentially involved in UVB-mediated premature senescence of human skin fibroblasts using siRNA technology. Mech Ageing Dev. 2008; 129: 109-19.

145. Wong KK, Maser RS, Bachoo RM, et al. Telomere dysfunction and Atm deficiency compromises organ homeostasis and accelerates ageing. Nature. 2003; 421: 643-8.

146. Calado RT, Young NS. Telomere maintenance and human bone marrow failure. Blood. 2008; 111: 4446-55.

147. Marrone A, Sokhal P, Walne A, et al. Functional characterization of novel telomerase RNA (TERC) mutations in patients with diverse clinical and pathological presentations. Haematologica. 2007; 92: 1013-20.

148. Yamamoto K, Nihrane A, Aglipay J, et al. Upregulated ATM gene expression and activated DNA crosslink-induced damage response checkpoint in Fanconi anemia: implications for carcinogenesis. Mol Med. 2008; 14: 167-74.

149. Meshorer E, Gruenbaum Y. Gone with the Wnt/Notch: stem cells in laminopathies, progeria, and aging. J Cell Biol. 2008; 181: 9-13.

150. Scaffidi P, Misteli T. Lamin A-dependent misregulation of adult stem cells associated with accelerated ageing. Nat Cell Biol. 2008; 10: 452-9.

151. Bergoglio V, Magnaldo T. Nucleotide excision repair and related human diseases. Genome Dyn. 2006; 1: 35-52.

152. Stout GJ, Blasco MA. Genetic dissection of the mechanisms underlying telomereassociated diseases: impact of the TRF2 telomeric protein on mouse epidermal stem cells. Dis Model Mech. 2009; 2: 139-56.

153. Aubert G, Lansdorp PM. Telomeres and aging. Physiol Rev. 2008; 88: 557-79. 
154. Mason PJ, Wilson DB, Bessler M. Dyskeratosis congenita - a disease of dysfunctional telomere maintenance. Curr Mol Med. 5: 159-70.

155. Kenyon J, Gerson SL. The role of DNA damage repair in aging of adult stem cells. Nucleic Acids Res. 2007; 35: 7557-65.

156. Nijnik A, Woodbine L, Marchetti C, et al. DNA repair is limiting for haematopoietic stem cells during ageing. Nature. 2007; 447: 686-90.

157. Chigancas V, Lima-Bessa KM, Stary A, et al. Defective transcription/repair factor IIH recruitment to specific UV lesions in trichothiodystrophy syndrome. Cancer Res. 2008; 68: 6074-83.

158. Redondo P, Prieto J, Munoz IG, et al. Molecular basis of xeroderma pigmentosum group C DNA recognition by engineered meganucleases. Nature. 2008; 456: 107-11.

159. de Gruijl FR, van Kranen HJ, Mullenders LH, et al. UV-induced DNA damage, repair, mutations and oncogenic pathways in skin cancer. J Photochem Photobiol B. 2001; 63: 19-27.

160. Couve-Privat S, Bouadjar B, Avril MF, et al. Significantly high levels of ultraviolet-specific mutations in the smoothened gene in basal cell carcinomas from DNA repair-deficient xeroderma pigmentosum patients. Cancer Res. 2002; 62: 7186-9.

161. Ya-Grosjean L, Sarasin A. UV-specific mutations of the human patched gene in basal cell carcinomas from normal individuals and xeroderma pigmentosum patients. Mutat Res. 2000; 450: 193-9.

162. Nijhof JG, van Pelt C, Mulder AA, et al. Epidermal stem and progenitor cells in murine epidermis accumulate UV damage despite NER proficiency. Carcinogenesis. 2007; 28: 792-800.

163. Siegl-Cachedenier I, Flores I, Klatt P, et al. Telomerase reverses epidermal hair follicle stem cell defects and loss of longterm survival associated with critically short telomeres. J Cell Biol. 2007; 179: 277-90.

164. Espada J, Varela I, Flores I, et al. Nuclear envelope defects cause stem cell dysfunction in premature-aging mice. J Cell Biol. 2008; 181: 27-35.

165. Sommer M, Poliak N, Upadhyay S, et al. DeltaNp63alpha overexpression induces downregulation of Sirt1 and an accelerated aging phenotype in the mouse. Cell Cycle. 2006; 5: 2005-11.

166. Bouillet P, Cory S, Zhang LC, et al. Degenerative disorders caused by $\mathrm{Bcl}-2$ deficiency prevented by loss of its $\mathrm{BH}$ - only antagonist Bim. Dev Cell. 2001; 1: 645-53.

167. Sharpless E, Chin L. The INK4a/ARF locus and melanoma. Oncogene. 2003; 22: 3092-8.

168. Lowe SW, Cepero E, Evan G. Intrinsic tumour suppression. Nature. 2004; 432: 307-15.

169. Zhao Y, Chaiswing L, Bakthavatchalu V, et al. Ras mutation promotes p53 activation and apoptosis of skin keratinocytes. Carcinogenesis. 2006; 27: 1692-8.

170. Gonzalez-Suarez E, Samper E, Flores $\mathrm{JM}$, et al. Telomerase-deficient mice with short telomeres are resistant to skin tumorigenesis. Nat Genet. 2000; 26: 114-7.

171. Cosme-Blanco W, Shen MF, Lazar AJ, et al. Telomere dysfunction suppresses spontaneous tumorigenesis in vivo by initiating p53-dependent cellular senescence. EMBO Rep. 2007; 8: 497-503.

172. Munoz P, Blanco R, Flores JM, et al. XPF nuclease-dependent telomere loss and increased DNA damage in mice overexpressing TRF2 result in premature aging and cancer. Nat Genet. 2005; 37: 106371.

173. Lu J, Rho O, Wilker E, et al. Activation of epidermal akt by diverse mouse skin tumor promoters. Mol Cancer Res. 2007; 5: $1342-52$.

174. Dahl C, Guldberg P. The genome and epigenome of malignant melanoma. APMIS. 2007; 115: 1161-76.

175. Yang SH, Andl T, Grachtchouk V, et al. Pathological responses to oncogenic Hedgehog signaling in skin are dependent on canonical Wnt/beta-catenin signaling. Nat Genet. 2008; 40: 1130-5.

176. Mimeault M, Batra SK. Recent insights into the molecular mechanisms involved in aging and the malignant transformation of adult stem/progenitor cells and their therapeutic implications. Ageing Res Rev. 2009; 8: 94-112.

177. Kannan K, Sharpless NE, Xu J, et al. Components of the Rb pathway are critical targets of UV mutagenesis in a murine melanoma model. Proc Natl Acad Sci USA. 2003; 100: 1221-5.

178. Shimizu T, Izumi $\mathrm{H}$, Oga $\mathrm{A}$, et al. Epidermal growth factor receptor overexpression and genetic aberrations in metastatic squamous-cell carcinoma of the skin. Dermatology. 2001; 202: 203-6.

179. Vidal VP, Ortonne N, Schedl A. SOX9 expression is a general marker of basal cell carcinoma and adnexal-related neoplasms. J Cutan Pathol. 2008; 35: 373-9.
180. Tanese K, Fukuma M, Yamada T, et al. Gprotein-coupled receptor GPR49 is up-regulated in basal cell carcinoma and promotes cell proliferation and tumor formation. Am J Pathol. 2008; 173: 835-43.

181. Aszterbaum M, Rothman A, Johnson RL, et al. Identification of mutations in the human PATCHED gene in sporadic basal cell carcinomas and in patients with the basal cell nevus syndrome. J Invest Dermatol. 1998; 110: 885-8.

182. Beachy PA, Karhadkar SS, Berman DM. Tissue repair and stem cell renewal in carcinogenesis. Nature. 2004; 432: 324-31.

183. Crowson AN. Basal cell carcinoma: biology, morphology and clinical implications. Mod Pathol. 2006; 19: S127-47.

184. Reinisch CM, Uthman A, Erovic BM, et al. Expression of BMI-1 in normal skin and inflammatory and neoplastic skin lesions. J Cutan Pathol. 2007; 34: 174-80.

185. Aszterbaum M, Epstein J, Oro A, et al. Ultraviolet and ionizing radiation enhance the growth of BCCs and trichoblastomas in patched heterozygous knockout mice. Nat Med. 1999; 5: 1285-91.

186. Mancuso M, Pazzaglia S, Tanori M, et al. Basal cell carcinoma and its development: insights from radiation-induced tumors in Ptch1-deficient mice. Cancer Res. 2004; 64: 934-41.

187. Dahmane N, Lee J, Robins $P$, et al. Activation of the transcription factor Gli1 and the Sonic hedgehog signalling pathway in skin tumours. Nature. 1997; 389: 876-81.

188. Fan H, Oro AE, Scott MP, et al. Induction of basal cell carcinoma features in transgenic human skin expressing Sonic Hedgehog. Nat Med. 1997; 3: 788-92.

189. Oro AE, Higgins K. Hair cycle regulation of Hedgehog signal reception. Dev Biol. 2003; 255: 238-48.

190. Grachtchouk V, Grachtchouk M, Lowe L, et al. The magnitude of hedgehog signaling activity defines skin tumor phenotype. EMBO J. 2003; 22: 2741-51.

191. Nilsson M, Unden AB, Krause D, et al. Induction of basal cell carcinomas and trichoepitheliomas in mice overexpressing GLI-1. Proc Natl Acad Sci USA. 2000; 97: 3438-43.

192. Athar M, Li C, Tang X, et al. Inhibition of smoothened signaling prevents ultraviolet B-induced basal cell carcinomas through regulation of Fas expression and apoptosis. Cancer Res. 2004; 64: 7545-52.

193. Nicolas M, Wolfer A, Raj K, et al. Notch1 functions as a tumor suppressor in mouse skin. Nat Genet. 2003; 33: 416-21. 
194. Gailani MR, Bale AE. Developmenta genes and cancer: role of patched in basal cell carcinoma of the skin. $J$ Natl Cancer Inst. 1997; 89: 1103-9.

195. Chen KG, Szakacs G, Annereau JP, et al. Principal expression of two mRNA isoforms (ABCB 5alpha and ABCB 5beta) of the ATP-binding cassette transporter gene ABCB 5 in melanoma cells and melanocytes. Pigment Cell Res. 2005; 18 : 102-12.

196. Hadnagy A, Gaboury L, Beaulieu R, et al. $\mathrm{SP}$ analysis may be used to identify cancer stem cell populations. Exp Cell Res. 2006; 312: $3701-10$

197. Klein WM, Wu BP, Zhao S, et al. Increased expression of stem cell markers in malignant melanoma. Mod Pathol. 2007; 20: 102-7.

198. Bongiorno MR, Doukaki S, Malleo F, et al. Identification of progenitor cance stem cell in lentigo maligna melanoma. Dermatol Ther. 2008; 21: S1-5.

199. Strizzi L, Abbott DE, Salomon DS, et al. Potential for cripto-1 in defining stem celllike characteristics in human malignant melanoma. Cell Cycle. 2008; 7: 1931-5.

200. Pinnix CC, Herlyn M. The many faces of Notch signaling in skin-derived cells. Pigment Cell Res. 2007; 20: 45865.

201. Gray-Schopfer VC, Cheong SC, Chong H, et al. Cellular senescence in naevi and immortalisation in melanoma: a role for p16? Br J Cancer. 2006; 95: 496-505.

202. Bardeesy N, Kim M, Xu J, et al. Role of epidermal growth factor receptor signaling in RAS-driven melanoma. Mol Cell Biol. 2005; 25: 4176-88.

203. Weeraratna AT, Jiang Y, Hostetter G, et al. Wnt5a signaling directly affects cell motility and invasion of metastatic melanoma. Cancer Cell. 2002; 1: 279-88.

204. Dhomen N, Reis-Filho JS, da Rocha DS, et al. Oncogenic Braf induces melanocyte senescence and melanoma in mice. Cancer Cell. 2009; 15: 294-303

205. Curtin JA, Fridlyand J, Kageshita T, et al. Distinct sets of genetic alterations in melanoma. N Engl J Med. 2005; 353: 2135-47.

206. Curtin JA, Busam K, Pinkel D, et al. Somatic activation of KIT in distinct subtypes of melanoma. J Clin Oncol. 2006; 24: 4340-6.

207. Grafstrom E, Egyhazi S, Ringborg U, et al. Biallelic deletions in INK4 in cutaneous melanoma are common and associated with decreased survival. Clin Cancer Res. 2005; 11: 2991-7.
208. Poynter JN, Elder JT, Fullen DR, et al. BRAF and NRAS mutations in melanoma and melanocytic nevi. Melanoma Res. 16: 267-73.

209. Jonsson G, Dahl C, Staaf J, et al. Genomic profiling of malignant melanoma using tiling-resolution arrayCGH. Oncogene. 2007; 26: 4738-48.

210. Smalley KS, Contractor R, Nguyen TK, et al. Identification of a novel subgroup of melanomas with $\mathrm{KIT} /$ cyclin-dependent kinase-4 overexpression. Cancer Res. 2008; 68: 5743-52.

211. Quintana E, Shackleton M, Sabel MS, et al. Efficient tumour formation by single human melanoma cells. Nature. 2008; 456: 593-8.

212. Metcalf $\mathrm{S}$, Crowson AN, Naylor M, et al. Imiquimod as an antiaging agent. $J \mathrm{Am}$ Acad Dermatol. 2007; 56: 422-5.

213. Bellizzi D, Rose G, Cavalcante P, et al. A novel VNTR enhancer within the SIRT3 gene, a human homologue of SIR2, is associated with survival at oldest ages. Genomics. 2005; 85: 258-63.

214. Fisher GJ, Wang ZQ, Datta SC, et al. Pathophysiology of premature skin aging induced by ultraviolet light. $N$ Engl J Med. 1997; 337: 1419-28.

215. Giannakou ME, Partridge L. The interaction between FOXO and SIRT1: tipping the balance towards survival. Trends Cell Biol. 2004; 14: 408-12

216. Mantel C, Broxmeyer HE. Sirtuin 1, stem cells, aging, and stem cell aging. Curr Opin Hematol. 15: 326-31.

217. Trapp J, Jung M. The role of NAD+ dependent histone deacetylases (sirtuins) in ageing. Curr Drug Targets. 2006; 7: 1553-60.

218. Seve M, Chimienti F, Devergnas S, et al. Resveratrol enhances UVA-induced DNA damage in $\mathrm{HaCaT}$ human keratinocytes. Med Chem. 2005; 1: 629-33.

219. Davids LM, du Toit E, Kidson SH, et al. A rare repigmentation pattern in a vitiligo patient: a clue to an epidermal stem-cell reservoir of melanocytes? Clin Exp Dermatol. 2009; 34: 246-8.

220. Yu BD, Mukhopadhyay A, Wong C. Skin and hair: models for exploring organ regeneration. Hum Mol Genet. 2008; 17: R54-9.

221. Gray-Schopfer V, Wellbrock C, Marais R. Melanoma biology and new targeted therapy. Nature. 2007; 445: 851-7.

222. Mimeault M, Hauke R, Mehta PP, et al. Recent advances on cancer stem/progenitor cell research: therapeutic implications for overcoming resistance to the most aggressive cancers. $J$ Mol Cell Med. 2007; 11: 981-1011.

223. Mimeault M, Batra SK. Recent advances on the development of novel anti-cancer drugs targeting cancer stem/progenitor cells. Drug Develop Res. 2008; 69: 415-30.

224. Tang JY, So PL, Epstein EH Jr. Novel Hedgehog pathway targets against basal cell carcinoma. Toxicol Appl Pharmacol. 2006; 224: 257-64.

225. Singh B, Schneider M, Knyazev P, et al. UV-induced EGFR signal transactivation is dependent on proligand shedding by activated metalloproteases in skin cancer cell lines. Int $J$ Cancer. 2009; 124: 531-9.

226. Stecca B, Mas C, Clement V, et al. Melanomas require HEDGEHOG-GLI signaling regulated by interactions between GLI1 and the RAS-MEK/AKT pathways. Proc Natl Acad Sci USA. 2007; 104: 5895-00.

227. Kirkwood JM, Tarhini AA, Panelli MC, et al. Next generation of immunotherapy for melanoma. J Clin Oncol. 2008; 26: 3445-55.

228. Remsberg JR, Lou H, Tarasov SG, et al. Structural analogues of smoothened intracellular loops as potent inhibitors of Hedgehog pathway and cancer cell growth. J Med Chem. 2007; 50: 4534-8.

229. Chen GS, Yu HS, Lan CC, et al. CXC chemokine receptor CXCR4 expression enhances tumorigenesis and angiogenesis of basal cell carcinoma. $\mathrm{Br} J$ Dermatol. 2006; 154: 910-8.

230. Kim Y, Lee YS, Choe J, et al. CD44-epidermal growth factor receptor interaction mediates hyaluronic acid-promoted cell motility by activating protein kinase $\mathrm{C}$ signaling involving Akt, Rac1, Phox, reactive oxygen species, focal adhesion kinase, and MMP-2. J Biol Chem. 2008; 283: 22513-28.

231. Qiu L, Wang Q, Di W, et al. Transient activation of EGFR/AKT cell survival pathway and expression of survivin contribute to reduced sensitivity of human melanoma cells to betulinic acid. Int $J$ Oncol. 2005; 27: 823-30.

232. Deng Y, Chang S. Role of telomeres and telomerase in genomic instability, senescence and cancer. Lab Invest. 2007; 87: 1071-6.

233. Harley CB. Telomerase and cancer therapeutics. Nat Rev Cancer. 2008; 8: 167-79.

234. Shay JW, Keith WN. Targeting telomerase for cancer therapeutics. Br J Cancer. 2008; 98: 677-83. 
235. Phatak P, Burger AM. Telomerase and its potential for therapeutic intervention. $\mathrm{Br} \mathrm{J}$ Pharmacol. 2007; 152: 1003-11.

236. Cortez-Gonzalez X, Zanetti M. Telomerase immunity from bench to bedside: round one. J Trans/ Med. 2007; 5: 12.

237. Brown AJ. Cholesterol, statins and cancer. Clin Exp Pharmacol Physiol. 2007; 34: 135-41.

238. Cooper MK, Wassif CA, Krakowiak PA, et al. A defective response to Hedgehog signaling in disorders of cholesterol biosynthesis. Nat Genet. 2003; 33: 508-13.

239. Bijlsma MF, Spek CA, Zivkovic D, et al. Repression of smoothened by patcheddependent (pro-) vitamin D3 secretion. PLoS Biol. 2006; 4: e232.

240. Williams JA, Guicherit OM, Zaharian BI, et al. Identification of a small molecule inhibitor of the hedgehog signaling pathway: effects on basal cell carcinoma-like lesions. Proc Natl Acad Sci USA. 2003; 100: 4616-21.

241. Epstein EH. Basal cell carcinomas: attack of the hedgehog. Nat Rev Cancer. 2008; 8: 743-54.

242. Garber K. Hedgehog drugs begin to show results. J Natl Cancer Inst. 2008; 100: 692-7.
243. Hodi FS, Friedlander P, Corless CL, et al. Major response to imatinib mesylate in KIT-mutated melanoma. J Clin Oncol. 2008; 26: 2046-51.

244. Knight LA, Di Nicolantonio F, Whitehouse $\mathbf{P}$, et al. The in vitro effect of gefitinib ('Iressa') alone and in combination with cytotoxic chemotherapy on human solid tumours. BMC Cancer. 2004; 4: 83.

245. Postovit LM, Margaryan NV, Seftor EA, et al. Human embryonic stem cell microenvironment suppresses the tumorigenic phenotype of aggressive cancer cells. Proc Natl Acad Sci USA. 2008; 105: 4329-34.

246. Nickoloff BJ, Hendrix MJ, Pollock PM, et al. Notch and NOXA-related pathways in melanoma cells. J Investig Dermatol Symp Proc. 2005; 10: 95-104.

247. Guo Y, Ma J, Wang J, et al. Inhibition of human melanoma growth and metastasis in vivo by anti-CD44 monoclonal antibody. Cancer Res. 1994; 54: 1561-5.

248. Ahrens T, Sleeman JP, Schempp CM, et al. Soluble CD44 inhibits melanoma tumor growth by blocking cell surface CD44 binding to hyaluronic acid. Oncogene. 2001; 20: 3399-408.

249. Bartolazzi A, Peach R, Aruffo A, et al. Interaction between CD44 and hyaluronate is directly implicated in the regulation of tumor development. J Exp Med. 1994; 180: 53-66.

250. Yokoyama S, Feige E, Poling LL, et al. Pharmacologic suppression of MITF expression via HDAC inhibitors in the melanocyte lineage. Pigment Cell Melanoma Res. 2008; 21: 457-63.

251. Tsao H, Atkins MB, Sober AJ. Management of cutaneous melanoma. $N$ Engl J Med. 2004; 351: 998-1012.

252. den Brok MH, Nierkens S, Figdor CG, et al. Dendritic cells: tools and targets for antitumor vaccination. Expert Rev Vaccines. 2005; 4: 699-710.

253. Sigalotti L, Covre A, Zabierowski S, et al. Cancer testis antigens in human melanoma stem cells: Expression, distribution, and methylation status. I Cell Physiol. 2008; 215: 287-91.

254. Aboody KS, Bush RA, Garcia E, et al. Development of a tumor-selective approach to treat metastatic cancer. PLOS ONE. 2006; 1: e23.

255. Gedye C, Quirk J, Browning J, et al. Cancer/testis antigens can be immunological targets in clonogenic CD133(+) melanoma cells. Cancer Immunol Immunother. 2009; 58: 1635-46. 